\title{
Aorist voice patterns in the diachrony of Greek
} The New Testament as a sample of Koine

\author{
Liana Tronci \\ University for Foreigners of Siena \\ tronci@unistrasi.it
}

\begin{abstract}
This paper deals with the aorist voice system in NT Greek and focuses on middlepassive markers, namely middle inflection, e.g. in the middle sigmatic aorist, and affixes $-\eta-/-\theta \eta$-, in the so-called passive aorist. The research is corpus-based and investigates the occurrences of ca. 1800 verbal items. According to the grammarians, in the NT both middle and passive aorists spread. The present study confirms this observation by providing a comprehensive account of the distribution of these forms, but also shows how they have functionally reorganised. Passive aorists spread at the expense of middle aorists in all kinds of intransitive constructions, namely passive, unaccusative, and reflexive, whereas middle aorists are either found in transitive middles, e.g. possessive, benefactive etc., or occur as deponent verbs in both transitive and intransitive clauses. The parameter transitive vs intransitive appears to be relevant for this functional reorganisation.
\end{abstract}

\section{Keywords}

Ancient Greek - aorist - voice - middle - passive - deponent - New Testament

\section{Introduction}

This paper deals with the verbal category of voice in Koine Greek and focuses on the aorist. As Browning (1983) and Horrocks (2010) pointed out, the aorist underwent major changes in voice from Ancient to Modern Greek: "the endings of the aorist middle $(-(\sigma) \alpha \dot{\mu \eta \nu}[(\mathrm{s})$ áme:n], -ó $\mu \eta \nu$ [-óme:n], etc.) were increasingly replaced by those of the aorist passive $\left(-(\theta) \eta \nu\left[-\left(\mathrm{t}^{\mathrm{h}}\right) \mathrm{e}: \mathrm{n}\right]\right.$, etc.)" (Horrocks 2010: 103) and, some centuries later, the replacement led to "[t]he reduction

(C) LIANA TRONCI, 2018 | DOI:10.1163/15699846-01802005

This is an open access article distributed under the terms of the prevailing CC-BY-NC license 
of the three voices of Classical Greek to two" (Browning 1983: 30). The avoidance of middle aorists increased over the centuries and overlapped with the collapse of the functional distinction between aorist and perfect. In the early Byzantine period, for instance, the perfect $\gamma \varepsilon$ ' $\gamma 0 v \alpha$ 'I have become' replaced the

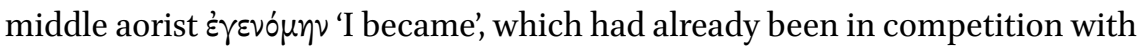
the passive $\dot{\varepsilon} \varepsilon v \eta \dot{\theta} \theta \eta \nu$ in the Koine (cf. Horrocks 2010: 256).

The aim of the paper is twofold. First, a synchronic analysis of the Hellenistic Greek system of voice is provided, through an in-depth investigation of the New Testament (henceforth NT). Second, some insights are developed concerning diachronic changes in the voice system from Classical to Hellenistic Greek. Since the language of the NT is "a reasonably close reflection of the everyday Greek of the majority of the literate population in the early centuries AD" (Horrocks 2010:147), the NT offers a good sample for investigating the changes that occurred in Greek in the first centuries CE.

The data analysis concerns both quantitative and qualitative aspects. To carry out the quantitative analysis, all the aorist occurrences were collected, with special emphasis on middle and passive aorists. The search for all the relevant forms was made by combining a manual search through the NA28 edition of the Greek New Testament (text available on the website http://www .nestle-aland.com/en/the-28-edition/) with electronic tools (e.g. TLG, Perseus 4.0 released on www.perseus.tufts.edu/hopper/). The research was refined by using lexica, e.g. Kittel \& Friedrich (1932-1936) and Thayer (1995). Our goal was to check how many middle aorists were replaced by passive aorists, how many were still functionally oppositive and how many were deponent or quasideponent forms. This quantitative analysis provides the basis for the qualitative one, which focuses on the values still retained by middle inflection in the Koine and the role of deponency within the voice system, with attention to aspects of both form and function.

Even though many studies have been devoted to the topic of voice, particularly middle voice, in Ancient Greek, most of them are not corpus-based, adopt a predominantly synchronic point of view, and mostly concern Homeric and Classical Greek. ${ }^{1}$ The perspective of this study is different in both respects. The corpus-based research provides a picture of how the voice system is organised within a single, but entire text. Even though the results obtained concern only the text investigated, they presumably reflect the voice system of the language in the first centuries CE. Further research could carry out a

1 Cf. Risselada (1987), Bakker (1994), Rijksbaron (2002), Allan (2003, 2014a, 2014b), Benedetti (2005, 2006, 2017), Alexiadou \& Doron (2012), and Tronci (2014) who, though adopting different perspectives, provide accounts of the voice in its entirety. 
corpus-based analysis of texts contemporary to the NT, with the aim of giving a more complete description of the voice system(s) in Koine and HellenisticRoman Greek. Some differences may also be found from one text to another, depending on the language register, the regional varieties, the speakers'/writers' knowledge of language and further sociolinguistic parameters. The issue of sociolinguistic variation might also be dealt with by comparing the texts which compose the NT, e.g. Gospels vs Acts vs Letters, which are different in terms of genre, style, author, and addressee, and, among Gospels, the more literary and Classical-shaped Gospel of Luke vs the more popular and spoken-like Gospel of Mark. However, this issue is too wide and complex to be dealt with here. The reader is referred to Porter (2000a, 200ob) for some preliminary analysis.

As far as the synchrony vs diachrony dichotomy is concerned, this study provides both a synchronic analysis of the aorist voice system in the NT and a diachronic comparison with both Homeric and Classical Greek.

The structure of the paper is as follows. In Section 2 a brief survey of the literature is provided. Section 3 is devoted to the analysis of data, by focusing on middle-inflected aorists in 3.1, passive aorists in 3.2 and some problematic cases in 3.3. In Section 4 the diachronic aspects of the aorist voice system are addressed, by comparing data from the NT with Homeric Greek (4.1) and Classical Greek (4.2). Finally some conclusions are drawn in Section 5 .

Before starting the next section, a terminological remark is necessary. By passive and middle aorists, I mean the passive- and the middle-inflected aorists, namely the inflectional classes marked by the affixes $-\eta-/ \theta \eta$ - and the middle inflection respectively, no matter what syntactic or semantic values these forms carry. Both labels are misleading when referring to the aorist, since not all passive aorists are true passives and middle aorists can overlap with the passive ones in some middle values, the term "middle" being applied in some recent studies, e.g. Kemmer (1993), also to some functional values regardless of the verbal forms which express them.

A brief survey of the literature

It is commonly agreed among scholars that the system of three voices-active, middle, and passive - in general remained the same in the $\mathrm{N}$ T, and more generally in Hellenistic Greek, as in the Classical language (cf. Moulton 1906:158-160; Blass, Debrunner \& Funk 1961:161). Besides the common idea of continuity with respect to Classical Greek, scholars also remark that there existed some differences between Classical and NT Greek, concerning in particular the relation- 
ship between middle and passive aorists. In his historical grammar, Jannaris (1897: §1478) stated (emphasis mine):

[The middle and passive voices] should sooner or later finish by being completely identified $[\ldots]$. The final outcome was then that the passive form soon gained ascendency over the middle and began to extrude it. One, probably also the primary, cause of this issue was that the subtle functions of the middle verb [...] had been lost sight of in the popular language, which in the great majority of cases dispensed altogether with such fine shades of thought [...], or, when indispensable, preferred to express them in a different, clearer mode, $[. .$.$] that is by means of a spe-$ cial complement $[\ldots]$. This circumstance naturally led to the disuse and final disappearance of all indirect middle verbs [...]. It is now obvious that, as this class had been the commonest, the number of middle verbs was reduced to a very small group as compared with the hosts of their rival or passive verbs.

In accordance with this analysis, McKay (1994: 26) stressed that the deponent middles of Classical Greek also take on passive morphology and he quotes the example of the deponent middle $\dot{\alpha} \pi \varepsilon x p i v \alpha \tau o$ 'he replied', which was replaced in the NT by "the normal Hellenistic aorist" $\alpha \pi \varepsilon x p i \theta \eta$ 'he replied' (cf. §3.1). This example also occurs in Caragounis (2004: 152), who noted that the phenomenon "is old having begun to occur already in A [= Classical, LT] authors". He also refers to Hatzidakis (1892: 193-194), who remarked that "[v]on vielen Verbis kannten aber auch die Attiker nur die Formen des Passivaoristus in medialer Bedeutung" ("for many verbs, however, even Attic authors used

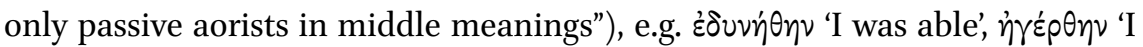

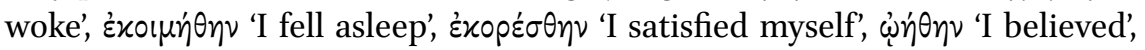

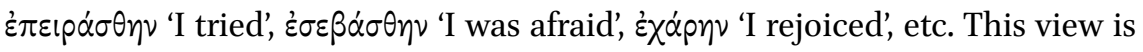
also shared by Aubrey's (2016:573) study, which is devoted to the topic of voice in Hellenistic Greek: "[f]rom Homeric to Classical and into Hellenistic, -(th)ēslowly expanded in two directions: (1) enveloping the semantically and syntactically passive events, and (2) encroaching on and gradually displacing sigmatic middles as the marking of choice for certain middle event types".

Some scholars also remarked that middle aorists were still abundant in NT Greek. This statement seems to conflict with the idea that passive aorists spread at the expense of the middle ones. Blass, Debrunner \& Funk (1961: 161), for instance, pointed out that in NT Greek there is a "tendency to merge the middle and the passive into a single voice", formally represented by the passive aorist, and that "NT authors in general preserve well the distinction between middle 
and passive" (1961: 165). Robertson (1934: 809) stated that "[i]n the flourishing period of the language [i.e. Classical Greek, LT] this [i.e. indirect middle, LT] was by far the most frequent use, but it finally faded before the active and the intensive (reflexive) pronoun or the passive. [...] But in general the indirect middle is abundant and free in the N.T.".

Summing up, two facts have been considered essential with respect to the aorist voice system of the NT: the spread of the "passive" aorists, which increasingly replaced the middle aorists, on the one hand, and the abundance of the middle aorists, on the other hand. Even though these two facts might appear to be inconsistent, this is not so. The fact that both classes are robustly attested in the NT seems to be in line with the state of affairs in Classical Greek. However, their functional distribution has changed with respect to Classical Greek. Our aim is to investigate the distribution of the two classes, in terms of both forms and functions, in order to determine the role of both inflectional opposition (middle vs active endings) and affixes contrast $(-\eta-/-\theta \eta-v s-\sigma \alpha-)$ in the aorist voice system of NT Greek.

The database for this research comprises 1838 verbal items (types) and a larger number of tokens. Some types are hapax legómena in the NT and are exclusively

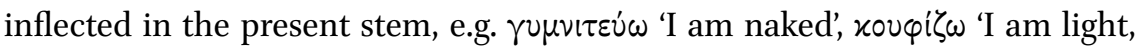

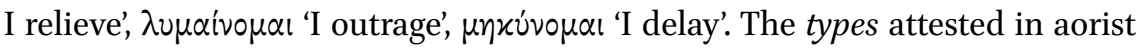
forms amount to 1016 by taking into account only finite moods (indicative, subjunctive, optative and imperative) and to 1222 by also counting non-finite forms (infinitives and participles). For simplicity's sake, our analysis only concerns finite forms.

Before turning to the analysis of voice, some rough quantitative data is useful. This data strictly concerns the level of forms, so "active", "middle" and "passive" refer to the verb morphology. Within the 1016 verbal items inflected in the aorist, more than half (580 types) are exclusively inflected in the active voice, 104 in the middle voice and 121 in the passive voice. Some examples are $\dot{\alpha} \lambda \dot{\alpha} \sigma \sigma \omega$

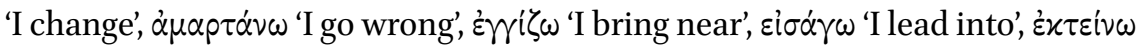

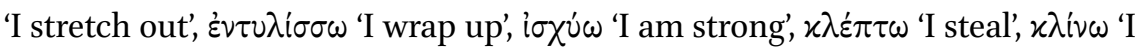

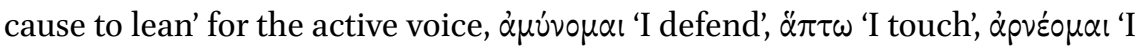

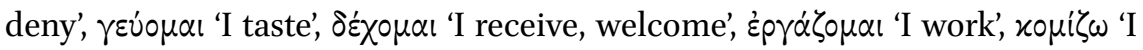

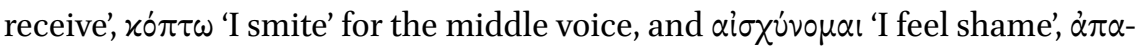
$\tau \alpha^{\prime} \omega$ 'I deceive', $\alpha \dot{\lambda} \lambda i \zeta o \mu \alpha \mathrm{l}$ 'I lie in the courtyard', $\beta \alpha \rho \varepsilon \omega^{\prime}$ 'I weight down, I depress',

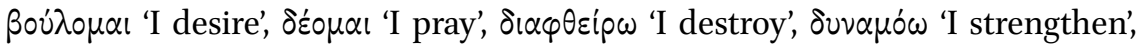


TABLE 1 Distribution of voice markers in finite aorists

Finite aorist types: 1016

Non-oppositive types Oppositive types

\begin{tabular}{lllr}
\hline Activa tantum & 580 & Active vs middle & 22 \\
Media tantum & 104 & Active vs passive & 167 \\
Passiva tantum & $\mathbf{1 2 1}$ & Middle vs passive & 13 \\
& & Active vs middle vs passive & 9 \\
Total & $\mathbf{8 0 5}$ & & $\mathbf{2 1 1}$ \\
\hline
\end{tabular}

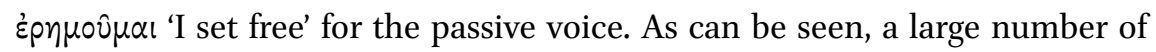
verbs which belong to the two latter classes are media tantum. Besides these forms, which do not feature any voice opposition, in the NT are also attested aorists which feature some voice opposition. The distribution is as follows. Only 9 types feature a tripartite opposition of active vs middle vs passive, e.g. $\beta \alpha \pi \tau i \zeta \omega$ 'I baptise', ع ${ }^{\alpha} \alpha \gamma \varepsilon \lambda i \zeta \omega$ 'I bring good news'; the remaining 202 types show bipartite oppositions: active vs passive (167 types), active vs middle (22 types), and middle vs passive (13 types). See Table 1 for a summary.

In the following sections, I show the semantic and syntactic values of the three aorist voices in both their oppositive and non-oppositive uses. More emphasis is given to middle and passive voices, because in Hellenistic Greek they increased as types and entered into competition as strategies for marking middle meanings such as reflexive (e.g. I washed myself), unaccusative (Igrew), benefactive (I bought the book for myself), possessive (I touched my eyes), etc. ${ }^{2}$ The middle voice tended to correlate with middle and deponent transitives, whereas the passive voice spread as a marker of intransitive structures, namely

2 Terminology is not consistent in the field of voice studies, as syntactic and semantic notions are not distinguished from one another. Unaccusative and reflexive are syntactic notions, like the passive. Unaccusative corresponds more or less to anticausative. Benefactive and possessive are, rather, semantic notions and relate to the co-occurrence on the subject argument of the semantic roles of beneficiary and possessor, respectively. I refer to Kulikov (2010), who illustrates the different terminologies, and to Kulikov (2013) and Kulikov \& Lavidas (2013), who account for the different voices in Greek and other Indo-European languages. Allan (2003) proposes a description of the middle voice in strictly semantic terms by distinguishing, for instance, the unaccusative middles in four semantic classes: (i) the Spontaneous Process middle, (ii) the Middle State/Process middle, (iii) the Body Motion middle, and (iv) the Collective Motion middle (see also Allan 2014b: 496-499). In this paper, however, I do not follow this classification. 
passive and unaccusative. The productivity of middle and passive aorists is not comparable. The aorist middle became a non-oppositive marker, whereas the aorist passive extended as an oppositive marker with respect to the active voice, by also replacing the intransitive middles, especially the unaccusative and the reflexive.

\subsection{Middle aorists}

In my database, most of the middle aorists are deponent verbs, namely verbs with middle morphology and an active meaning in all forms of the paradigm.

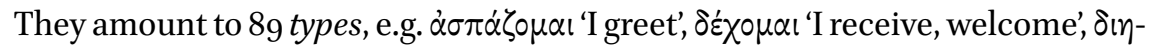

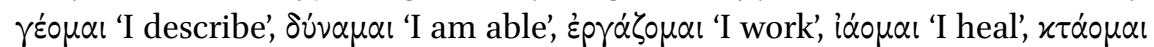

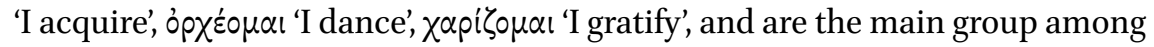
the aorists exclusively attested in the middle voice in the NT (104 types). They are attested in both intransitive and transitive structures, e.g. ópX'́s in (1a) and $\delta \dot{\varepsilon} \chi 0 \mu \alpha$ เ 'I receive, welcome' in (lb).

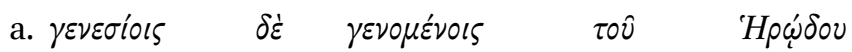

birthday:DAT PTCL happened:PTCP ART.GEN Herod:GEN

$\dot{\omega} \rho x \dot{\eta} \sigma \alpha \tau 0 \quad \dot{\eta} \quad \vartheta \gamma \alpha \dot{\tau} \tau p$

dance:AOR.MID.3SG ART.NOM daughter:NOM ART.GEN

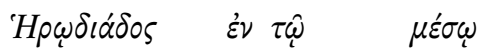

Herodias:GEN in ART.DAT middle:DAT

'But on Herod's birthday, the daughter of Herodias danced before them' (Matthew 14:6)

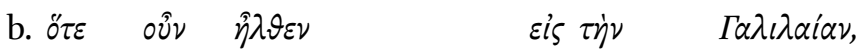
when PTCL come:AOR.ACT.3Sg to ART.ACC Galilee:ACC

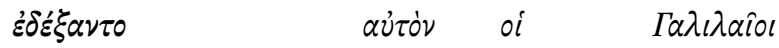
welcome:AOR.MID.3PL 3SG.ACC ART.NOM Galileans:NOM 'So when he came to Galilee, the Galileans welcomed him' (John 4:45)

The functional equivalence between the middle morphology of deponent verbs and the active morphology of non-deponent verbs had been already remarked on by Mayser (1906: 112) in his grammar on Ptolemaic Greek papyri and was recently emphasised by Lavidas \& Papangeli (2007:105) who state: "the active and the middle/passive transitive interchange without any difference in meaning since the Koine period". Further evidence of this functional equivalence is given by the passive counterparts for the transitive deponents. In 9 of the 13 types which are inflected as both middle and passive, the morphological difference correlates with the functional opposition between transitive and 


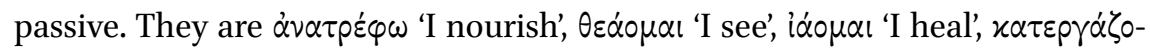

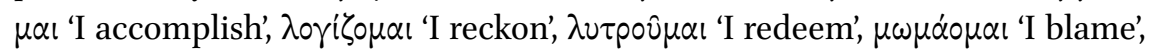

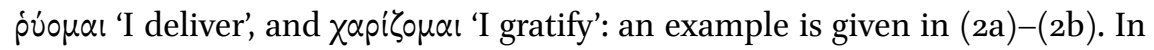

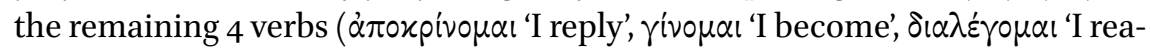
son', દ̇ $\mu \beta p \mu \alpha \dot{\alpha} \sigma \mu \alpha$ l 'I groan'), the voice difference appears to be meaningless; see $(3 \mathrm{a})-(3 \mathrm{~b})$ :

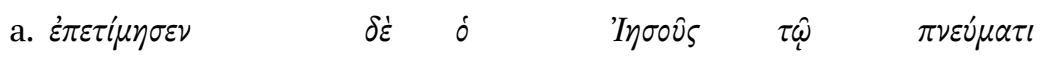
rebuke:AOR.ACT.3SG PTCL ART.NOM Jesus:NOM ART.DAT spirit:DAT

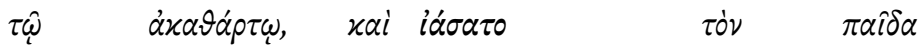
ART.DAT unclean:DAT and heal:AOR.MID.3SG ART.ACC boy:ACC 'But Jesus rebuked the unclean spirit, and healed the boy' (Luke 9:42)

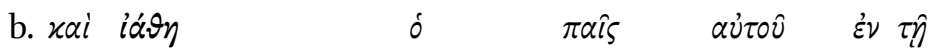
and heal:AOR.PASS.3SG ART.NOM boy:NOM 3SG.GEN in ART.DAT

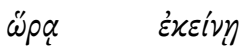
hour:DAT DEM.DAT 'and the servant was healed at that hour' (Matthew 8:13)

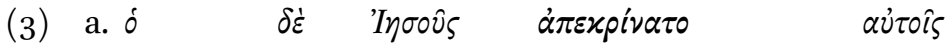
ART.NOM PTCL Jesus:NOM answer:AOR.MID.3SG 3PL.DAT 'but Jesus answered them' (John 5:17)

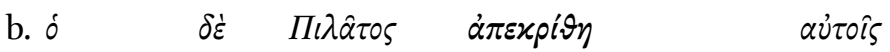
ART.NOM PTCL Pilate:NOM answer:AOR.PASS.3SG 3PL.DAT $\lambda \varepsilon^{\prime} \gamma \omega \nu$ saying:PTCP 'and Pilate answered them, saying' (Mark 15:9)

Out of the total number of 148 types inflected as middle aorists, 105 occur in biargumental structures and 43 in intransitive structures. Among the biargumental verbs, 99 are fully transitive and 6 occur with the genitive ( $\alpha \nu \tau i \lambda \alpha \mu \beta \dot{\alpha}-$

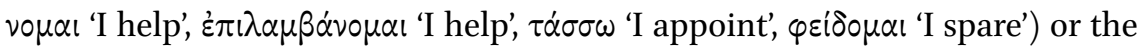

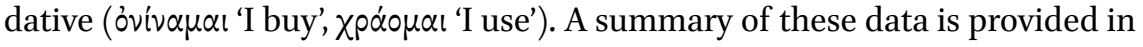
Table 2.

Let us return to the issue of deponency, which has been debated ever since the 19th century (cf. Kühner \& Gerth 1892: §324; 1898: §377) and has received renewed attention in recent years (cf. Lavidas \& Papangeli 2007, Ladewig 2010, Grestenberger 2014, Campbell 2015). In particular, Lavidas \& Papangeli propose an account of both semantic and syntactic approaches to deponency 
TABLE 2 Distribution of middle aorists in transitive vs intransitive structures

Middle aorists: 148 types

$\begin{array}{lr}\text { In biargumental structures: } & 105 \\ \text { + accusative (fully transitive) } & 99 \\ \text { + genitive/dative } & 6 \\ \text { In intransitive structures } & 43\end{array}$

and an insightful diachronic analysis from Ancient to Modern Greek. As they cogently argue, the proposed unified analysis of deponent verbs in terms of either semantic features or syntactic parameters does not match with Greek data. According to their investigation, "the data [i.e. Greek diachronic data, LT] lack any systematic pattern: an initially deponent verb may have an active variant with identical interpretation that is used in parallel or, even, instead of the deponent" (Lavidas \& Papangeli 2007: 116). ${ }^{3}$

In the light of these considerations, one could interpret as "quasi-deponent" the verbs in the database which feature middle morphology in all aorist occurrences of the NT, while not being elsewhere deponent, namely $\dot{\alpha} \pi \circ i i \tau \omega$ 'I

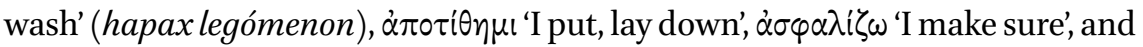

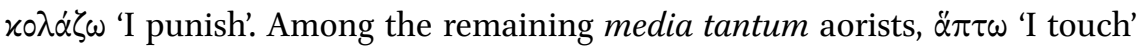
and $x \circ \mu i \zeta \omega$ 'I receive' are each attested only once with active morphology, $\ddot{\alpha} \pi \tau \omega$

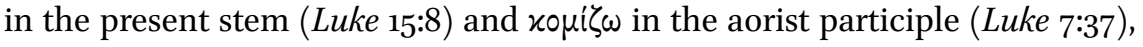
and $\alpha$ $\rho \chi \omega$ 'I begin' is attested only twice in the active voice (Mark 10:42 and Romans 15:12). For some of the remaining verbs, namely $\alpha \dot{\alpha} \varepsilon \mid \lambda \varepsilon \dot{\varepsilon} \omega$ 'I warn', $\sigma \nu \mu-$

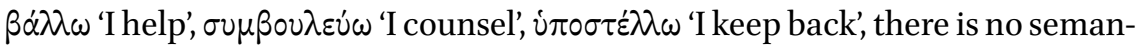
tic difference between active and middle forms, whereas there is a difference for the last verbs of our list, namely $x \alpha \tau \alpha \rho \tau i \zeta \omega$ 'I prepare' vs $\varkappa \alpha \tau \alpha \rho \tau i \zeta o \mu \alpha$ ' 'I am

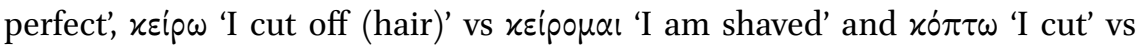
xó $\pi \tau 0 \mu \alpha$ ' 'I mourn'. For instance, the active forms (present stem) of $x o ́ \pi \tau \omega$ are transitive, e.g. (4a), whilst its middle forms (both aorists and imperfects) are transitive/intransitive, e.g. (4b): the meaning 'to mourn, to mourn for' of middle forms is presumably a semantic extension from the reflexive middle 'to beat or strike oneself'.

3 For further insights into the issue, with special emphasis on media tantum futures, cf. also Tronci (2017). 


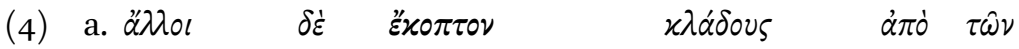
other:NOM PTCL cut:IMPF.ACT.3PL branches:ACC from ART.GEN

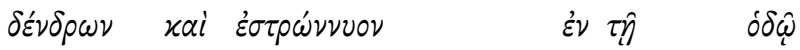
trees:GEN and spread:IMPF.ACT.3PL in ART.DAT road:DAT 'and others cut branches from the trees and spread them on the road' (Matthew 21:8)

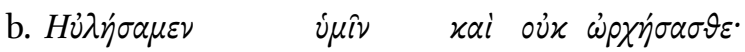

play:AOR.ACT.1PL 2PL.DAT and not dance:AOR.MID.2PL

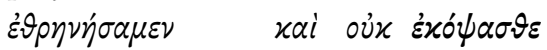

sing:AOR.ACT.1PL and not mourn:AOR.MID.2PL

'we played the flute for you, and you did not dance; we sang a dirge, and you did not mourn' (Matthew 11:17)

The semantic disjunction between active and middle forms of the same verb is evidence of the loss of the syntactic, i.e. diathetic, relationship between them (see below for further details). This phenomenon had already begun in Late Classical Greek and the new deponent verbs attested in Hellenistic Greek are evidence of this (cf. Lavidas \& Papangeli 2007: 105-107).

In the NT, there are also aorists which feature oppositive middle inflection. They are less frequent than the media tantum aorists and they also occur in both intransitive and transitive structures. In (5a)-(5c) I provide examples of some oppositive values of the middle, namely possessive, benefactive and unaccusative:

a. $\lambda \alpha \beta \dot{\omega} \nu$

visp

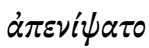

$\tau \dot{\alpha} \varsigma$

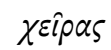

taking:PTCP water:ACC wash:AOR.MID.3SG ART.ACC hands:ACC

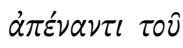
óx $x$ ov

before ART.GEN crowd:GEN

'[Pilate] took some water, washed his hands before the crowd' (Matthew 27:24)

b. évo

àंó $\tau \hat{\eta} \varsigma \quad \tau \psi \mu \hat{\eta} \varsigma$,

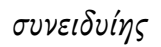

keep.back:AOR.MID.3SG from ART.GEN proceed:GEN knowing:PTCP

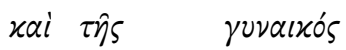

and ART.GEN wife:GEN

'[Ananias] kept back for himself part of the proceeds with his wife's knowledge' (Acts 5:2) 


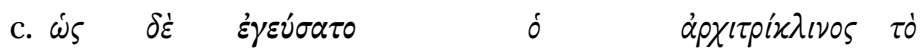
when PTCL taste:AOR.MID.3SG ART.NOM steward:NOM ART.ACC

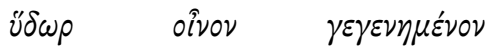
water:ACC wine:ACC become:PTCP 'When the head steward tasted the water that had been turned to wine' (John 2:9)

Paired middle vs active aorists are very rare in the NT; an example is (6):

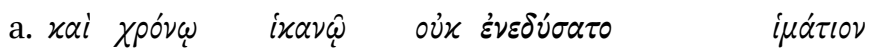
and time:DAT long:DAT not wear:AOR.MID.3SG clothes:ACC 'For a long time this man had worn no clothes' (Luke 8:27)

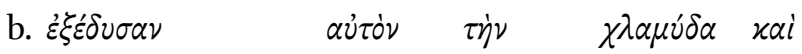
strip:AOR.ACT.3PL 3SG.ACC ART.ACC robe:ACC and

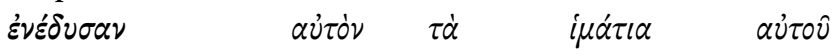
wear:AOR.ACT.3PL 3SG.ACC ART.ACC clothes:ACC 3SG.GEN 'they stripped him of the robe and put his own clothes back on him' (Matthew 27:31)

Much more frequent are the cases in which only the middle is attested, even though the verb is not deponent and the active aorist is elsewhere attested, for instance in Classical Greek, e.g. (7a)-(7b):
a. $\circ \mathcal{x}$ i $\mu \varepsilon \hat{\imath} \quad \mu \varepsilon$
$\xi_{\varepsilon} \xi \varepsilon \lambda \dot{\varepsilon} \xi \alpha \sigma \vartheta \varepsilon$,
$\dot{\alpha} \lambda \lambda^{\prime} \dot{\varepsilon} \gamma \dot{\omega}$

not 2PL.NOM 1SG.ACC choose:AOR.MID.2PL but 1SG.NOM

$\dot{\varepsilon} \xi \varepsilon \lambda \varepsilon \xi \dot{\alpha} \mu \eta \nu$

choose:AOR.MID.1SG 2PL.ACC

'You did not choose me, but I chose you' (John 15:16)

b. oi $\delta \dot{\varepsilon} \quad \dot{\alpha} x o u ́ \sigma \alpha v \tau \varepsilon \varsigma \quad \dot{x} \chi \dot{\alpha} p \eta \sigma \alpha \nu \quad$ xai ART.NOM PTCL hearing:PTCP be.delighted:AOR.PASS.3PL and

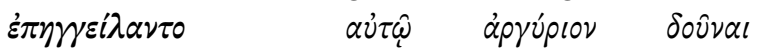
promise:AOR.MID.3PL 3SG.DAT money:ACC give:INF 'When they heard this, they were delighted and promised to give him money' (Mark 14:11)

The distribution of middle aorists is evidence of the functional decline of middle inflection in Hellenistic Greek. Even though it is widespread in many verb forms, the occurrences in which middle inflection expresses some middle 
values are very rare. It is preserved as a form, though it has lost its oppositive values. According to Caragounis (2004:152), middle inflection in its entirety, the present stem included, is no longer productive as a voice marker in NT Greek. In interpreting the passage 15:2 of the Gospel of Matthew, in which the middle

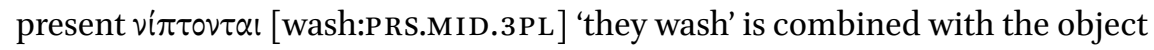
$\tau \dot{\alpha} \varsigma$ [ART.ACC] $\chi \varepsilon \hat{i} \rho \alpha \varsigma$ [hands:ACC] $\alpha \dot{\tau} \tau \hat{\omega} \nu$ [3PL.GEN] 'their hands', Caragounis remarks: " $[t]$ he use of the middle with an expressed object indicates that the feeling for the fine distinction between the active and the middle has been lost" and quotes as further evidence the passages Acts 7:58, 26:21, Ephesians 5:16, and Titus 2:7. In my opinion, there are some essential differences between the present middle and the aorist middle in the NT. The present middle preserved all the functions of middle inflection, from the intransitive (the passive and the unaccusative) to the transitive ones (see Tronci forthcoming, who investigates the functional distribution of the middle forms belonging to all tenses and moods in the Gospel of Matthew for a total number of 979 occurrences). The aorist middle continued to exist as a form but lost its main functional values, e.g. unaccusative and reflexive, which were increasingly expressed by the passive aorist. The present middle, instead, still correlated with the intransitive middle values and tended to be replaced by the active in transitive middle values, namely benefactive and possessive. The analysis of changes in voice morphology by Lavidas (2009: 108) is in line with this view: "[f]rom the Hellenistic period, the marking of the benefactive ('personal interest') meaning by non-active [i.e. middle, LT] morphology begins to be abandoned".

\subsection{Passive aorists}

The distribution of passive aorists within the database is as follows: 121 verbs are exclusively inflected as passive aorists, 167 are coupled with active aorists, 13 with middle aorists, and 9 with both of them. This picture allows us to have a clearer idea concerning the functions of passive aorists in the NT. The main function is to express the passive, e.g. (8a), and the unaccusative, e.g. (9a), by means of opposition to active morphology, e.g. (8b) and ( $9 b)$ :

a. Tóte $\delta$

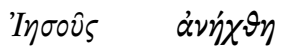

sis $\tau \dot{\eta} \nu$

then ART.NOM Jesus:NOM lead:AOR.PASS.3SG into ART.ACC

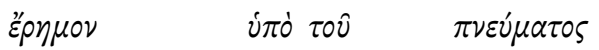

wilderness:ACC by ART.GEN spirit:GEN

'Then Jesus was led by the Spirit into the wilderness' (Matthew 4:1)'

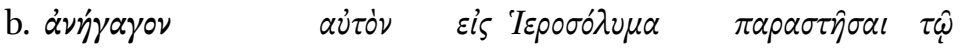

lead:AOR.ACT.3PL 3SG.ACC to Jerusalem:ACC present:INF ART.DAT 
xupíw

Lord:DAT

'[Joseph and Mary] brought him up to Jerusalem to present him to the Lord' (Luke 2:22)

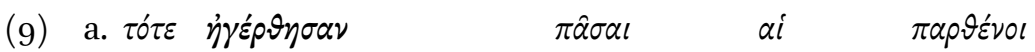

then weak.up:AOR.PASS.3PL QUANT.NOM ART.NOM virgins:NOM

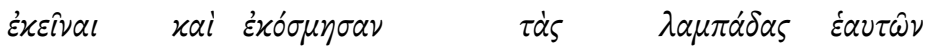

DEM.NOM and trim:AOR.ACT.3PL ART.ACC lamps:ACC REFL.GEN

'Then all the virgins woke up and trimmed their lamps' (Matthew 25:7)

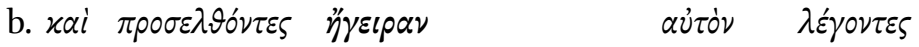

and coming:PTCP weak.up:AOR.ACT.3PL 3SG.ACC saying:PTCP

'So they came and woke him up saying' (Matthew 8:25)

The occurrence of the same verbal morphology in passives and unaccusatives is syntactically motivated. Both structures are characterised by the movement of an argument from underlying object status to subject status. The difference between the two clauses concerns the underlying subject of the clause; there is a subject present in the deep structure in the passive (whether expressed or absent in the surface structure), but one does not occur in the unaccusative (cf., among others, La Fauci \& Tronci 2009). For instance, the anticausative events which occurred after the death of Jesus are shaped into a sequence of unaccusative passive aorists in the Gospel of Matthew (27: 51-53).

In some cases, the choice between passive and unaccusative is a matter of interpretation, e.g. in (10a) compared to the transitive in (1ob). This fact is hardly surprising, since the two voices, not being formally distinguished in Greek, are not expected to diverge much in meaning either (cf. Jankuhn 1969: 18-25).

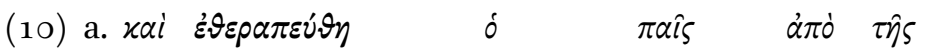

and heal:AOR.PASS.3SG ART.NOM boy:NOM from ART.GEN

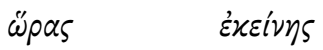

moment:GEN DEM.GEN

'and the boy (was) healed from that moment' (Matthew 17:18)

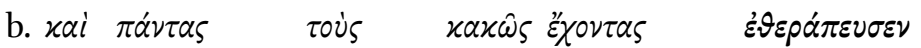

and QUANT.ACC ART.ACC sick having:PTCP heal:AOR.ACT.3SG

'and he healed all who were sick' (Matthew 8:16) 
Many passive aorists occur in the NT as passiva tantum (121 types). A lit-

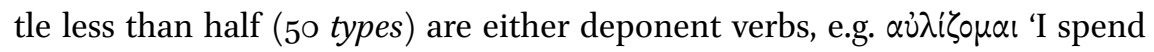

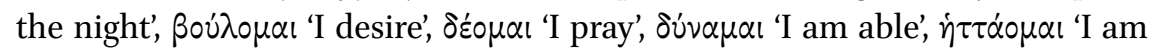
overcome', i $\lambda \alpha \dot{\sigma} \sigma \kappa \mu \alpha$ l 'I make reconciliation', or quasi-deponent verbs, namely verbs which were coupled with a corresponding transitive causative in Classical Greek, but are exclusively attested in non-active voices in the NT, e.g.

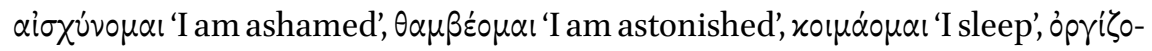

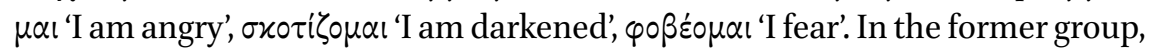

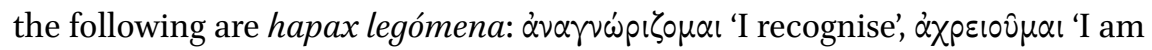

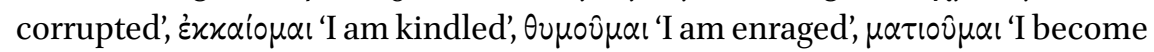

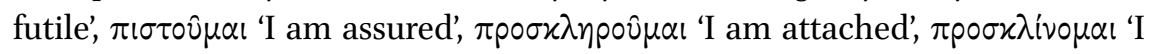

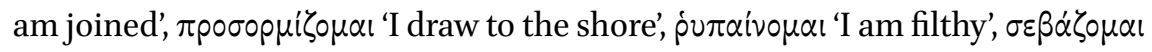

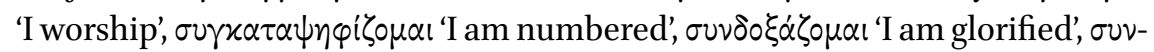

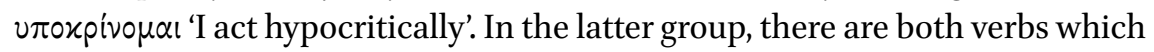

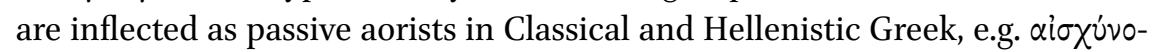
$\mu \alpha \mathrm{l}(11 \mathrm{a})-(11 \mathrm{~b})$, and verbs which occur as passive aorists in Hellenistic Greek but

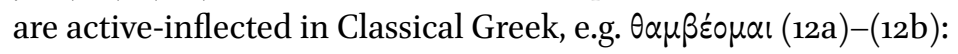

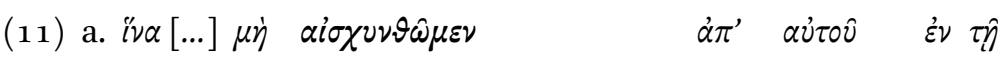

COMP not be.ashamed:AOR.PASS.1PL from 3SG.GEN in ART.DAT

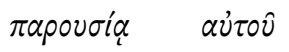

coming:DAT 3SG.GEN

'[abide in him] so that we may not shrink from him in shame at his coming' (1John 2:28)

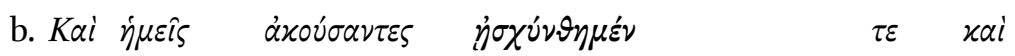
and 1PL.NOM hearing:PTCP be.ashamed:AOR.PASS.1PL PTCL and

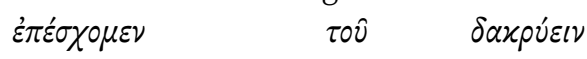

control:AOR.ACT.1PL ART.GEN cry:INF

'Then we were ashamed and controlled our tears' (Pl. Phaedo 117e)

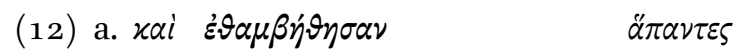

and be.astounded:AOR.PASS.3PL QUANT.NOM

'and they were all amazed' (Mark 1:27)

b. $\pi \hat{\varsigma} \varsigma \quad \delta^{\prime} \quad \varepsilon^{2} \hat{\alpha} \mu \beta \eta \sigma \varepsilon \nu \quad x \lambda v \omega \dot{\nu} /$

QUANT.NOM PTCL be.astounded:AOR.ACT.3SG hearing:PTCP

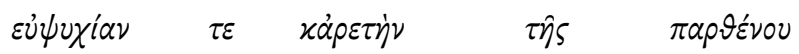

courage:ACC PTCL and.brave:ACC ART.GEN maiden:GEN

'and each man marvelled, as he heard the maiden's brave speech' (E. Iph. Aul. 1561-1562) 
The verb $\theta \alpha \mu \beta \varepsilon$ co $\mu \alpha$ is a good example to illustrate the voice changes in Ancient Greek. The verb $\theta \alpha \mu \beta \varepsilon \dot{\varepsilon} \omega$ is attested in both present and aorist stems with active voice from Homer until Classical Greek, as shown by the aorist $\dot{\varepsilon} \theta \dot{\alpha} \mu$ $\beta \eta \sigma \varepsilon \nu$ in (12b) and the imperfect $\varepsilon \theta \dot{\alpha} \mu \beta \varepsilon \circ v$ attested in Homeric poems, Pindar and Herodotus. The verb is commonly considered to be intransitive, the occurrences with a noun in the accusative commonly being interpreted as constructions with an accusative of relation, e.g. Өd $\mu \beta \eta \sigma \alpha \nu$ [be.astounded:AOR.ACT.3PL]

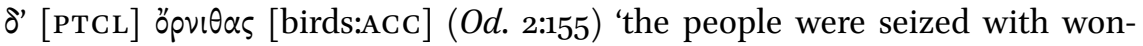

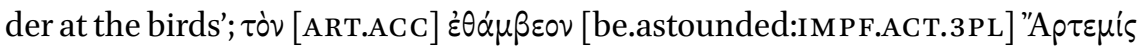

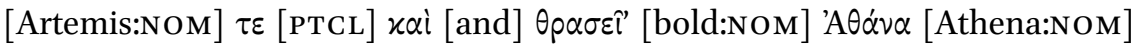
(Pi. N. 3:50) 'Artemis and bold Athena gazed at him with wonder'; $\tau$ f́pas [monstrous.thing:ACC] $\delta$ ' [PTCL] غ̇ं $\dot{\alpha} \mu \beta$ ○ov [be.astounded:IMPF.ACT.3PL] (A. Supp. 570) 'and they were astonished at the monstrous thing'. In the NT the verb is exclusively attested with non-active morphology, namely with passive morphology in the aorist, see (12a), and with middle morphology in the present stem, see (12c):

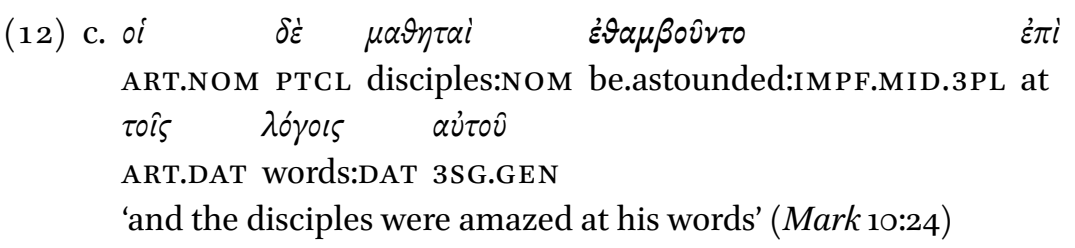

Summing up, the verb $\theta \alpha \mu \beta \varepsilon ́ \omega$ was activum tantum in Homeric and Classical Greek ${ }^{4}$ and became deponent (medium or passivum tantum) in Post-Classical Greek. This phenomenon is part of a larger phenomenon which concerned many verbs throughout the history of the Greek language. According to Lavidas \& Papangeli (2007: 108), "[ $n$ ]ot all deponents display stable behaviour through the different stages of Greek. In many cases, the deponent verbs have changed to actives, and, in other cases, they have attracted other verbs from the class of actives". The syntactic and semantic behaviour of the verbs which changed from active to middle/passive and vice versa remains the same, because the change concerns only verb morphology; cf. Lavidas \& Papangeli (2007: 121). Deponency does not involve diathesis, since the morphology of deponent verbs, be they activa or media/passiva tantum, is not oppositive.

4 The verb is especially attested in Homeric poems and in tragic authors, so it belongs to the poetic lexicon. 
Let us now turn to the 71 types of passiva tantum aorists that belong to non-deponent verbs. Most of them are attested in the NT with both active and middle morphology in stems other than the aorist. As for the aorist, only the passive is attested. See for instance the present transitive of $\alpha \nu \alpha x p i v \omega$ 'I judge' vs the aorist passive in (13a), the future transitive of $\pi \lambda \eta \theta \dot{v} v \omega$ 'I multiply' in (13b) vs the aorist passive in (13c), the perfect transitive of $\pi i \pi \rho \alpha \dot{\sigma} \kappa \omega$ 'I sell' in (13d) vs the aorist passive in $(13 \mathrm{e})$ :

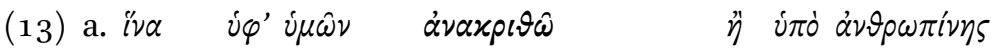 COMP by 2PL.GEN judge:AOR.PASS.1SG or by human:GEN

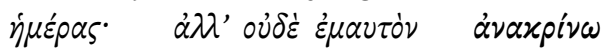 court:GEN but not REFL.ACC judge:PRS.ACT.1SG} '[But with me it is a very small thing] that I should be judged by you or by any human court. In fact, I do not even judge myself' ( 1 Corinthians $4: 3)$

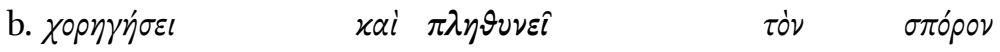
supply:FUT.ACT.3sG and multiply:FUT.ACT.3SG ART.ACC seed:ACC $i \mu \hat{\omega} \nu$ 2PL.GEN

'[He who supplies seed to the sower and bread for food] will supply and multiply your seed for sowing' (2 Corinthians 9:10)

c. $\eta \ddot{\xi} \xi \eta \sigma \varepsilon \nu$ o $\quad$ a increase:AOR.ACT.3SG ART.NOM people:NOM and

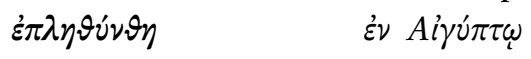
multiply:AOR.PASS.3SG in Egypt:DAT 'the people increased and multiplied in Egypt' (Acts 7:17)

d. $\dot{\alpha} \pi \varepsilon \lambda \vartheta \dot{\omega} \nu \quad \pi \dot{\varepsilon} \pi \rho \alpha x \varepsilon \nu \quad \pi \dot{\alpha} \nu \tau \alpha \quad$ ö $\sigma \alpha$ going:PTCP sell:PF.ACT.3SG QUANT.ACC REL.ACC

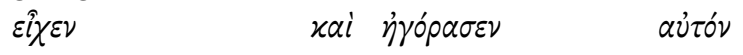
have:IMPF.ACT.3SG and buy:AOR.ACT.3SG 3SG.ACC '[who, on finding one pearl of great value,] went and sold all that he had and bought it' (Matthew 13:46)

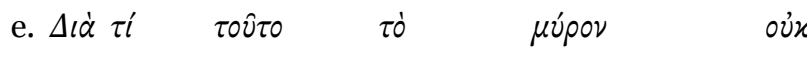
for Q.ACC DEM.NOM ART.NOM ointment:NOM not

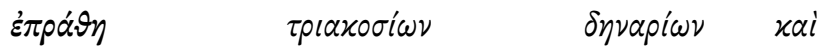
sell:AOR.PASS.3SG three.hundred:GEN denarii:GEN and 
$\begin{array}{ll}\varepsilon \delta \delta o ́ \vartheta & \pi \tau \omega \chi 0 i ̂ \\ \text { give:AOR.PASS.3SG } & \text { poor:DAT }\end{array}$

'Why was this ointment not sold for three hundred denarii and given to the poor?' (John 12:5)

Within the database, only the verb $\chi \alpha i p \omega$ is inflected as a passive in the aorist stem and as an active in the present stem without any difference in meaning. In both cases it means 'to rejoice, to be glad' (on this verb, cf. Tronci 2005: 20, fn. 14):

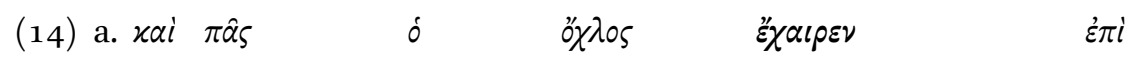
and QUANT.NOM ART.NOM people:NOM rejoice:IMPF.ACT.3SG at

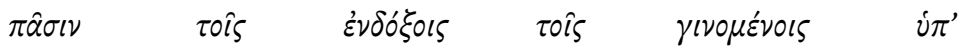
QUANT.DAT ART.DAT glorious:DAT ART.DAT produced:PTCP by aं่น0ิ

3SG.GEN

'and all the people rejoiced at all the glorious things that were done by him' (Luke 13:17)

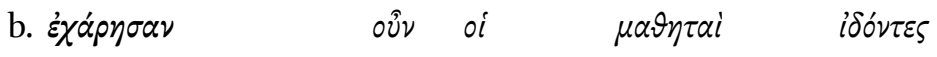
rejoice:AOR.PASS.3PL PTCL ART.NOM disciples:NOM seeing:PTCP tòv xúplov

ART.ACC Lord:ACC

'Then the disciples were glad when they saw the Lord' (John 20:20)

Among the 71 types of passiva tantum aorists, there are also some hapax legó-

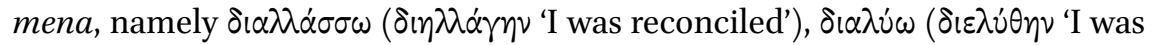

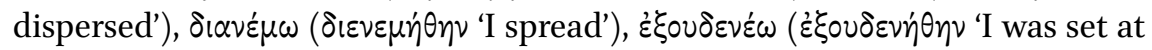

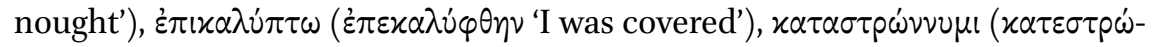

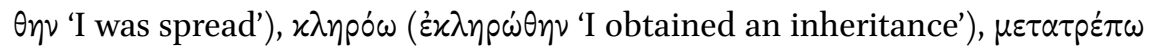

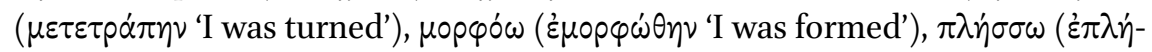

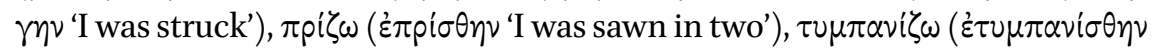
'I was tortured'), i $\pi \circ \lambda \varepsilon i \pi \omega$ ( $\dot{\pi} \pi \lambda \varepsilon i \varphi \theta_{\eta \nu}$ 'I was left'), and some verbs which are attested in all stems with non-active morphology, namely passive morphology in the aorist and future, and middle morphology in the present, imperfect, future and perfect. A couple of examples of each type follow in $(15 a)-(15 b)$ and (16a)-(16b) respectively:

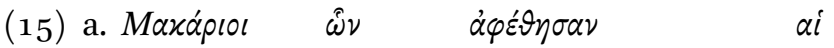
blessed:NOM REL.GEN forgive:AOR.PASS.3PL ART.NOM 


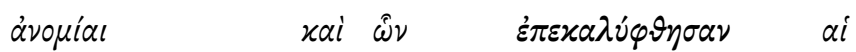

lawless.deeds:NOM and REL.GEN cover:AOR.PASS.3PL ART.NOM

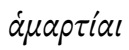

sins:NOM

'Blessed are those whose lawless deeds are forgiven, and whose sins are covered' (Romans 4:7)

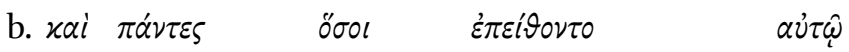

and QUANT.NOM REL.NOM obey:IMPF.MID.3PL 3SG.DAT

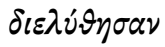

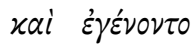

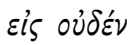

disperse:AOR.PASS.3PL and become:AOR.MID.3PL to nothing:ACC 'and all who followed him were dispersed and came to nothing' (Acts $5: 36)$

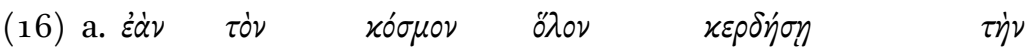
COMP ART.ACC world:ACC whole:ACC gain:AOR.ACT.3SG ART.ACC

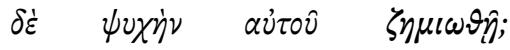

PTCL soul:ACC 3SG.GEN forfeit:AOR.PASS.3SG

'[For what will it profit a man] if he gains the whole world and forfeits his soul?' (Matthew 16:26)

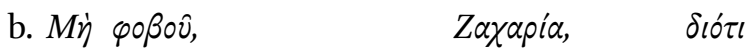
not be.afraid:PRS.MID.2SG Zechariah:VOC сомP

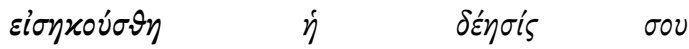
hear:AOR.PASS.3SG ART.NOM prayer:NOM 2SG.GEN

'Do not be afraid, Zechariah, for your prayer has been heard' (Luke 1:13)

A few passive aorists expectedly feature the affix $\eta$-. Following the alphabetic order of the dictionaries, they are $\alpha \pi \varepsilon \sigma \tau \rho \alpha \dot{\varphi} \eta \nu$ 'I turned away', $\delta \eta \lambda \lambda \alpha$ ' $\eta \nu$ 'I was

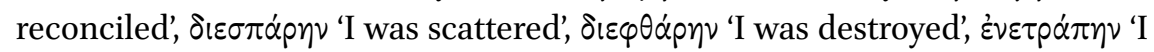

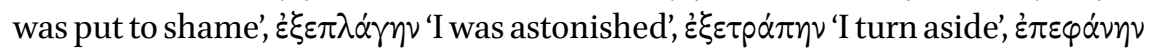
'I appeared', $\varkappa \alpha \tau \varepsilon x \alpha ́ \eta \nu$ 'I was burned up', $\varkappa \alpha \tau \eta \lambda \lambda \alpha \gamma \eta \nu$ 'I was reconciled', $\varkappa \alpha \tau \varepsilon v \cup$ $\eta \nu$

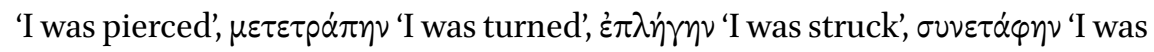

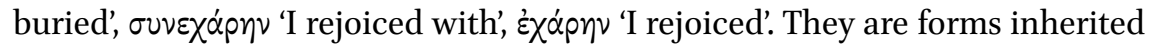
from Homeric and Classical Greek which continued to exist in Post-Classical Greek, even though the affix $\eta$ - was not productive. The semantic and syntactic values of the passive aorists with $\eta$ - are comparable to those of the aorists with $-\theta \eta-;$ see the passive (17a) and the unaccusative (17b): 


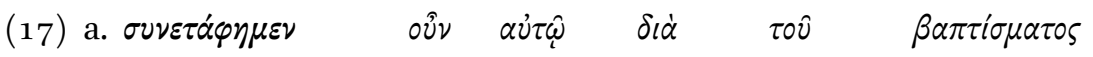
bury:AOR.PASS.1PL PTCL 3SG.DAT through ART.GEN baptism:GEN

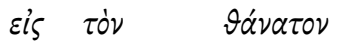

into ART.ACC death:ACC

'We were buried therefore with him by baptism into death' (Romans 6:4)

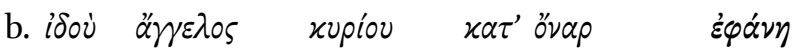
PTCL angel:NOM Lord:GEN in dream:ACC appear:AOR.PASS.3SG $\alpha \dot{v} \tau \hat{\omega} \quad \lambda \varepsilon \dot{\gamma} \gamma \nu$ 3SG.DAT saying:PTCP 'an angel of the Lord appeared to him in a dream, saying' (Matthew 1:20)

Before summing up, I discuss the case of the 5 verbs, namely $\alpha$ toxpivo $\mu \alpha$ ' 'I

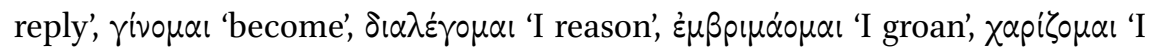
gratify', which occur as both middle and passive aorists in the NT without any

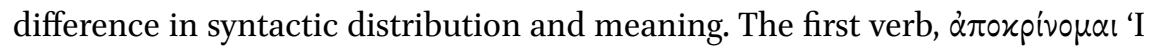
reply', is attested $109 \times$ as a passive aorist and $7 \times$ as a middle aorist; see examples above in $(3 a)-(3 b)$. The quantitative relationship between the two forms in the NT is inverted with respect to Classical Greek. In Classical Greek, the passive aorist is rare: it occurs $2 \times$ in Thucydides and $1 \times$ in Herodotus, whilst the middle aorist occurs $18 \times$ in Thucydides, $83 \times$ in Xenophon, $29 \times$ in Plato, $20 \times$ in Demosthenes. Furthermore, by comparing passive and middle aorists of $\alpha$ roxpivopal in Thucydides, two different meanings emerge, namely, 'to reply' for the middle and 'to be separated' for the passive:
a. oi
$\delta \dot{\varepsilon} \quad K o p i v \vartheta 101$

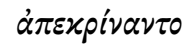
avioîs

ART.NOM PTCL Corinthians:NOM reply:AOR.MID.3PL 3PL.DAT 'The Corinthians replied to them' (Th. 1:28)

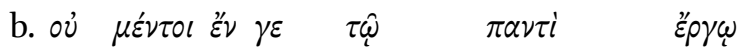
not PTCL in PTCL ART.DAT QUANT.DAT engagement:DAT

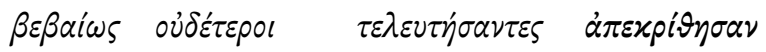
certainly neither:NOM finishing:PTCP separate:AOR.PASS.3PL 'Still, in respect of the whole engagement neither side when they parted had a decided advantage' (Th. 4:72)

In Post-Classical Greek, the passive aorist became more frequent than the middle and replaced it in its meaning 'to answer, to reply'. LSJ s.v. remarks that this use "condemned by Phryn.86, is unknown in earlier Att., exc[ept] in Pherecr. 51, 


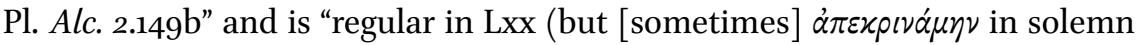

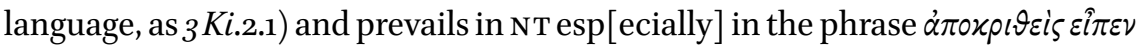

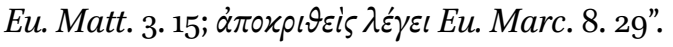

Let us now turn to the second verb of the list, namely rivoral 'I become'. The

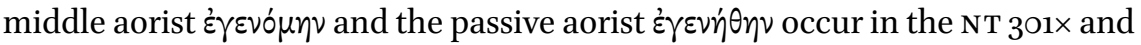
$40 \times$ respectively. The passive aorist is attested in the Gospels of Matthew, Mark and Luke, in the book of Acts, in the Pauline Epistles, and in the first Letter of Peter. In some cases, the two forms show the same textual distribution, e.g. (19a)-(19b):

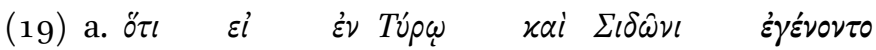

COMP COMP in Tyre:DAT and Sidon:DAT happen:AOR.MID.3PL

ai $i v \nu \alpha ́ \mu \varepsilon l s$ ai

ART.NOM mighty.works:NOM ART.NOM happened:PTCP in 2PL.DAT 'For if the mighty works done in you had been done in Tyre and Sidon' (Matthew 11:21)

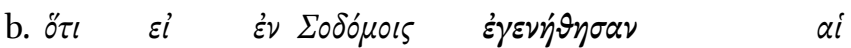

COMP COMP in Sodom:DAT happen:AOR.PASS.3PL ART.NOM

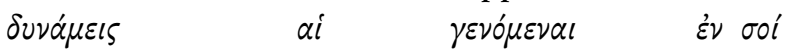

mighty.works:NOM ART.NOM happened:PTCP in 2SG.DAT

'For if the mighty works done in you had been done in Sodom' (Matthew 11:23)

However, the middle aorist also occurs in impersonal constructions with the meaning 'it happened', followed by an accusative plus infinitive (19c) or a coordinate finite clause (19d):

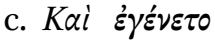
aìtò

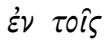
$\sigma a ́ \beta \beta a \sigma l v$
and happen:AOR.MID.3SG 3SG.ACC in ART.DAT Sabbath:DAT

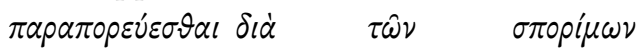

go:INF through ART.GEN grain.fields:GEN

'And it happened that one Sabbath he was going through the grain fields' (Mark 2:23)

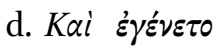

$\dot{\varepsilon} \nu \hat{\eta} \quad \dot{\eta} \mu \varepsilon_{\rho} \alpha \quad \tau \hat{\eta}$

and happen:AOR.MID.3SG in ART.DAT day:DAT ART.DAT

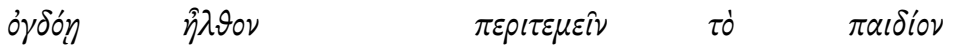

eighth:DAT come:AOR.ACT.3PL circumcise:INF ART.ACC child:ACC 'And it happened that on the eighth day they came to circumcise the child' (Luke 1:59) 
The passive aorist is never found in these kinds of clauses in the NT. It occurs with a lexical subject and adjectival or nominal predicative of the subject, e.g. (19e)-(19f):
e. $\delta$
$\delta \dot{\varepsilon} \quad \alpha \dot{x} \times 0 \dot{\sigma} \sigma \alpha \varsigma$
$\tau \alpha \hat{\tau} \tau \alpha$
$\pi \varepsilon p i \lambda u \pi \circ S^{2}$

ART.NOM PTCL hearing:PTCP DEM.ACC sad:NOM

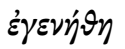
become:AOR.PASS.3SG

'But when he heard these things, he became very sad' (Luke 18:23)

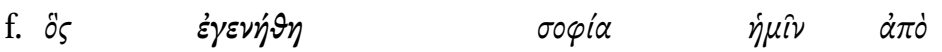 \\ REL.NOM become:AOR.PASS.3SG wisdom:NOM 1PL.DAT from \\ $\vartheta \varepsilon 0 \hat{v}$ \\ God:GEN \\ '[Christ Jesus,] who became to us wisdom from God' (1 Corinthians 1:30)
}

The syntactic and semantic distribution of the passive aorist is more restricted than that of the middle aorist. Even though some uses of the two forms overlap, they do not appear to be free variants in the NT.

The verbs $\delta\llcorner\alpha \lambda \dot{\gamma} \gamma \sigma \mu \alpha \mathrm{l}$ 'I reason' and $\dot{\mu} \mu \beta \rho \mu \alpha \dot{\alpha} 0 \mu \alpha \mathrm{l}$ 'I groan' can be quickly dealt with because their middle and passive aorists are rarely attested in the NT $(\delta \varepsilon \varepsilon-$

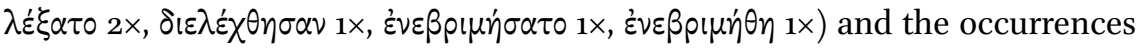
of $\delta เ \varepsilon \lambda \varepsilon^{\prime} \xi \alpha \tau 0 / \delta เ \varepsilon \lambda \dot{\varepsilon} \chi \theta \eta \sigma \alpha \nu$, on the one hand, and $\dot{\varepsilon} v \varepsilon \beta p \mu \eta \dot{\eta} \sigma \alpha \tau 0 / \varepsilon \dot{\varepsilon} \varepsilon \beta p \mu \mu \dot{\eta} \theta \eta$, on the other hand, show the same syntactic distribution and meaning.

The last verb of the list is interesting because shows the emergence of a new

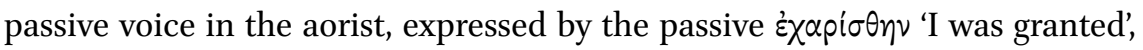
besides the deponent transitive '̇ं $\alpha p$ attested $7 \times$ in the NT, whereas the passive is attested only once. The following pair shows the syntactic and semantic difference between the two forms, the former being transitive and the latter passive:

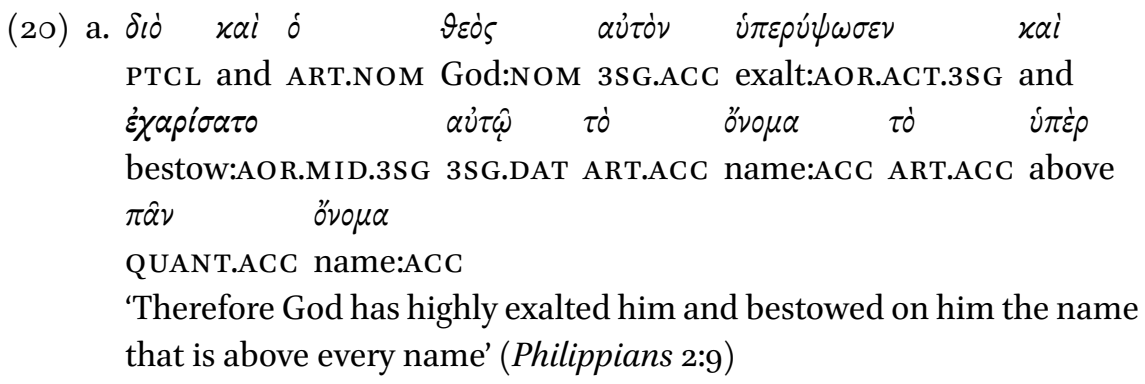




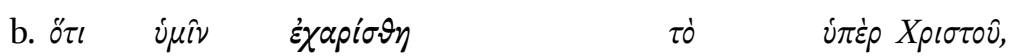

COMP 2PL.DAT be.granted:AOR.PASS.3SG ART.NOM for Christ:GEN

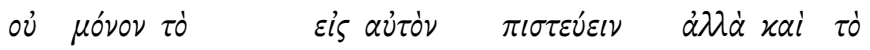
not only ART.NOM in 3SG.ACC believe:INF but also ART.NOM

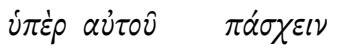

for 3SG.GEN suffer:INF

'For it has been granted to you that for the sake of Christ you should not only believe in him but also suffer for his sake' (Philippians 1:29)

Summing up, passive aorists are very productive in the NT. They spread at the expense of middle aorists in unaccusatives and intransitive deponents. Middle aorists continued to exist in transitive uses of deponent and quasi-deponent verbs, but lost most intransitive uses. As I show in Section 4, intransitive occurrences of middle aorists were attested in Homeric poems and had already decreased in number in Classical Greek. In Homeric poems we also find pairs of middle and passive aorists derived from the same verb and both occurring in

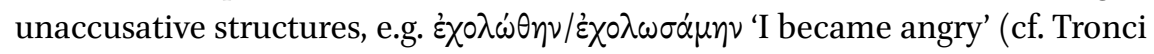
2011 and examples $27 \mathrm{a}-27 \mathrm{~b}$ below).

The seemingly chaotic outcome of the competition between passive and middle aorists is evidence of some instability. However, there is some evidence that the system was being reorganised in binary terms: on the one hand, the diathesis expressed by both active and middle aorists, which increasingly correlated with transitive structures; on the other hand, the diathesis expressed by passive aorists, which embraced the core intransitive values of middle, namely the passive and the unaccusative, and extended into intransitive deponents. The reassessment shows the emergence of the syntactic feature transitive vs intransitive within the middle diathesis (cf. Section $5)$.

\subsection{Some problematic cases}

Three occurrences in my corpus do not fit into the illustrated patterns. They concern the verbs $\dot{\alpha} \gamma \alpha \lambda \lambda \alpha^{\alpha} \alpha \omega$ 'I rejoice exceedingly', $\alpha \pi \Delta \lambda \circ v^{\prime} \omega$ 'I wash' and $\beta \alpha \pi \tau i \zeta \omega$ 'I baptise.' The first verb could be interpreted as a quasi-deponent, if it were not for the occurrence of one unaccusative active aorist: see discussion below. As for the latter two verbs, their middle aorists $\dot{\alpha} \pi \varepsilon \lambda \circ v \sigma \dot{\alpha} \mu \eta \nu, \dot{\varepsilon} \beta \alpha \pi \tau \iota \sigma \dot{\alpha} \mu \eta \nu$ are commonly interpreted as passives, though they cannot be passive, because sigmatic middles are never passive in Ancient Greek, cf. Wackernagel (1926:137-138), Pré$\operatorname{vot}(1935: 17-18)$, Schwyzer (1990: 757), Ambrosini (1996:21). In the following we argue for a different reading through an investigation of all the occurrences of these verbs. 
The first case concerns the verb $\alpha \gamma \alpha \lambda \lambda \alpha^{\alpha} \omega$ 'I rejoice exceedingly', which is more frequent as deponent $\alpha \gamma \alpha \lambda \lambda i \alpha \dot{\alpha} \mu \alpha$, according to $L S J$ s.v. In the NT, the verb is attested $4 \times$ with middle inflection, e.g. (21a), and $1 \times$ with active inflection, e.g. $(21 b)$, without any semantic and syntactic difference between them:
a. 'Ev $\alpha \dot{v} \pi \hat{\eta} \quad \tau \hat{\eta} \quad \ddot{\omega} \rho \alpha \quad \dot{\eta} \gamma \alpha \lambda \iota \dot{c} \sigma \alpha \tau 0$
in 3SG.DAT ART.DAT occasion:DAT rejoice:AOR.MID.3SG in $\tau \hat{\omega} \quad \pi \nu \varepsilon \dot{u} \mu \alpha \tau l \quad \tau \hat{\omega} \quad \dot{\alpha} \gamma \dot{i} \omega$ xai $\varepsilon i \pi \varepsilon v$ ART.DAT spirit:DAT ART.DAT holy:DAT and say:AOR.ACT.3SG 'On that same occasion Jesus rejoiced in the Holy Spirit and said' (Luke $10: 21)$

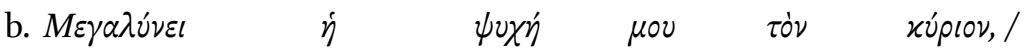 exalt:PRS.ACT.3SG ART.NOM soul:NOM 1SG.GEN ART.ACC Lord:ACC

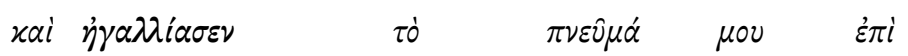 and rejoice:AOR.ACT.3SG ART.NOM spirit:NOM 1SG.GEN in $\tau \hat{\omega} \quad \vartheta \varepsilon \hat{\omega} \quad \tau \hat{\omega} \quad \sigma \omega \tau \hat{p} \rho i \quad \mu O v$ ART.DAT God:DAT ART.DAT Savior:DAT 1SG.GEN 'My soul exalts the Lord, and my spirit has begun to rejoice in God my Savior' (Luke 1:46-47)

The inflectional opposition does not correlate with any difference concerning voice, unless we read $(21 \mathrm{~b})$ as a transitive-causative clause 'my soul let my spirit rejoice in God'. This would be a contrived interpretation, however, and for this reason we prefer to adopt the common reading and try to explain otherwise the occurrence of active inflection (cf. also commentaries on Luke's Gospel, e.g. Carroll 2012: 47-48). The verb $\dot{\alpha} \gamma \alpha \lambda \lambda_{1} \alpha \omega$ is attested $4 \times$ as a sigmatic mid-

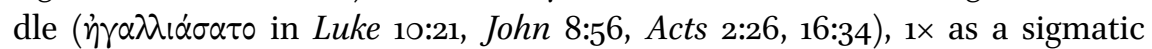
active (ì $\gamma \alpha \lambda i \alpha \sigma \varepsilon \nu$ in Luke $1: 47$ ) and $1 \times$ as a passive (infinitive $\alpha \gamma \alpha \lambda \lambda_{1} \alpha \theta \hat{\eta} \nu \alpha \iota$ in John 5:35). In the present stem, the verb occurs $4 \times$ as a middle $\left(\dot{\alpha} \gamma \alpha \lambda \lambda_{1} \hat{\alpha} \sigma \theta \varepsilon\right.$ in Matthew 5:12, 1 Peter 1:6, 1:8; $\alpha \gamma \alpha \lambda \lambda_{\imath} \omega \mu \varepsilon v 0$ in 1 Peter 4:16) and $1 \times$ as an active ( $\dot{\alpha} \gamma \alpha \lambda, \hat{\omega} \mu \varepsilon \nu$ in Revelation 19:7), without any difference in meaning between active and middle. The verb is also attested in the Old Testament, consistently inflected in the middle voice. According to some commentaries, e.g. Plummer (1960: 31-32), the entire passage of the Song of Mary is modelled on the Song of Hannah in 1 Sam. 2:1-10, in which the verb $\alpha \gamma \alpha \lambda \lambda_{1} \alpha \omega$ does not occur, however.

Let us return to the active inflection of the verb in $(21 \mathrm{~b})$, which is awkward with respect to the consistent picture provided by the other occurrences of the verb and needs, therefore, some further explanation. The passage has received much attention among scholars because the two verbs that occur in it present 
some peculiarities with respect to both voice and tense. Firstly, $\mu \varepsilon \gamma \alpha \lambda v^{\prime} \varepsilon t$ is a present and $\eta \gamma \alpha \lambda i \alpha \sigma \varepsilon v$ is an aorist. The combination is unusual because the two verbs are coordinated and both refer to the present time. To explain this oddity, Buth (1984) argues that the passage was literally translated by Luke from an original Hebrew poem. In Hebrew, tense shifting is a matter of aesthetics and poetry and does not correlate with any shift in time reference. The Greek translator, presumably the evangelist Luke, "accurately transmitted the Hebrew poetic form and preserved the poetic tension of the Hebrew in the Greek" (1984: 74). By following this suggestion, it can also be argued that the active voice

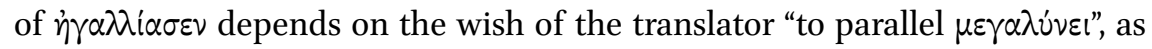
proposed by Méndez (2016: 558, fn. 3). In sum, the peculiarity of $\eta \gamma \alpha \lambda i \alpha \sigma \varepsilon \nu$ as far as tense and voice are concerned could be explained in terms of an ad hoc creation to translate an original Hebrew poem (cf. Plummer 1960: 30 who argues that Jews knew many of the Old Testament lyrics by heart and that Mary had recourse to these in the moment of exultation). A comparable hypothesis can be proposed for the active present $\alpha \gamma \alpha \lambda$ i $\omega \mu \varepsilon \nu$ (Revelation 19:7). The verb is preceded by $\chi \alpha i \rho \omega \mu \varepsilon v$ and followed by $\delta \omega \sigma \omega \mu \varepsilon v$, both of them active. The morpho-phonetic parallelism, on the one hand, and the semantic closeness to $\chi \alpha i p \omega \mu \varepsilon v$, on the other hand, could have allowed the verb $\alpha \gamma \alpha \lambda \lambda เ \hat{\omega} \mu \varepsilon v$ to take an active inflection. Consider, however, that the middle form $\alpha \gamma \alpha \lambda \lambda \iota \dot{\omega} \mu \varepsilon \theta \alpha$ is provided by some manuscripts, even though it is presumably to be interpreted as lectio facilior.

The second problematic case concerns the middle aorist of ¿ $\pi \circ \lambda \circ v^{\omega} \omega$ 'I wash' in (22a), which is commonly interpreted as a passive (cf. commentaries by Phillips 2002:129 and Hays 2011: 97 who translate it with 'you have been washed' and 'they were washed' respectively) along with the two subsequent passive

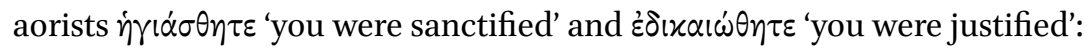

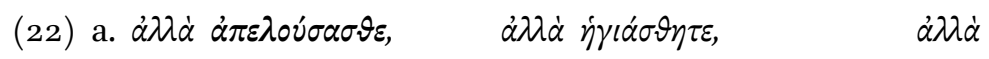
but wash:AOR.MID.2PL but sanctify:AOR.PASS.2PL but

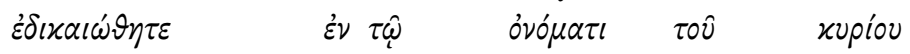
justify:AOR.PASS.2PL in ART.DAT name:DAT ART.GEN Lord:GEN

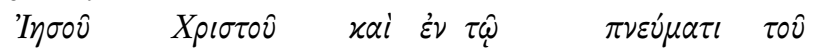
Jesus:Gen Christ:Gen and in ART.DAT spirit:DAT ART.GeN $\vartheta \varepsilon 0 \hat{v} \quad \dot{\eta} \mu \hat{\omega} \nu$

God:GEN 1PL.GEN

'But you were washed, you were sanctified, you were justified in the name of the Lord Jesus Christ and by the Spirit of our God' ( 1 Corinthians 6:11) 
The second occurrence of the verb in the NT is again with middle inflection, but the clause is transitive:

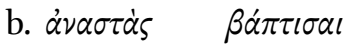

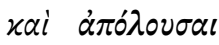
$\tau \dot{\alpha} \varsigma$
rising:PTCP baptise:AOR.MID.2SG and wash:AOR.MID.2SG ART.ACC

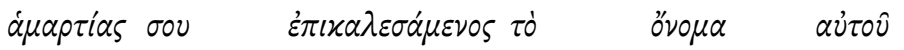
sins:ACC 2SG.GEN calling:PTCP ART.ACC name:ACC 3SG.GEN

'Rise and get yourself baptised and wash away your sins, calling on his name' (Acts 22:16)

With respect to the transitive clause in (22b), the clause in (22a) could be either passive 'you were washed' or reflexive 'you washed yourselves'. In both cases, the act of washing is metaphorical and implies 'to wash of sin': according to Hays (2011: 97) "Paul alludes here to [the] baptism". The interpretation as a passive has presumably been encouraged by the occurrence of the passive aorists $\dot{\eta} \gamma \dot{\alpha} \sigma \theta \eta \tau \varepsilon$ and $\dot{\varepsilon} \delta \varkappa \alpha \iota \dot{\theta} \theta \eta \tau \varepsilon$ in the sequence. We consider that the difference in voice between the middle $\dot{\alpha} \pi \varepsilon \lambda \circ \dot{\sigma} \sigma \alpha \sigma \theta \varepsilon$ and the passives $\dot{\eta} \gamma(\dot{\alpha} \sigma \theta \eta \tau \varepsilon$ and $\dot{\varepsilon} \delta$ $\chi \alpha i \omega^{\prime} \theta \eta \tau \varepsilon$ is meaningful. The middle aorist could be interpreted as a reflexive, thus implying an involvement of the subject in the event. The act of washing themselves $\left(\dot{\alpha} \pi \varepsilon \lambda \circ v^{\prime} \sigma \alpha \sigma \theta \varepsilon\right)$ could therefore imply sanctification $(\dot{\eta} \gamma / \alpha \dot{\sigma} \sigma \theta \eta \tau \varepsilon)$ and justification ( $\left(\dot{\delta} \delta\left(x \alpha \iota \omega^{\prime} \theta \eta \tau \varepsilon\right)\right.$ : the three verbs "are three descriptions of the one fundamental transformation that has occurred for those who now belong to Christ" (Hays 2011:98). This reading allows us to account for the sigmatic middle $\dot{\alpha} \pi \varepsilon \lambda \circ v^{\sigma} \sigma \alpha \sigma \theta \varepsilon$ in accordance with the syntactic and semantic values of middle aorists which are attested in the NT as well as in Homeric and Classical Greek.

Let us now turn to the third problematic case, which concerns the following occurrence of the verb $\beta \alpha \pi \tau i \zeta \omega$ 'I wash, I baptise':
a. xai $\pi \dot{\nu} \nu \tau \varepsilon \zeta$
sis $\tau \dot{s} \nu$
$M \omega \sigma \hat{\eta \nu}$
$\varepsilon \beta \alpha \pi \tau i \sigma \alpha \nu \tau 0$
$\dot{\varepsilon} v$
and QUANT.NOM into ART.ACC Moses:ACC baptise:AOR.MID.3PL in $\tau \hat{\eta}$$$
\nu \varepsilon \varphi \dot{\lambda} \lambda \eta \quad \text { xai } \dot{\varepsilon}^{2} \tau \hat{\eta}
$$
$\vartheta \alpha \lambda \alpha \dot{\sigma \sigma \sigma}$
ART.DAT cloud:DAT and in ART.DAT sea:DAT
'and all were baptised into Moses in the cloud and in the sea' (1 Corinthi- ans 10:2)

The middle aorist $\dot{\varepsilon} \beta \alpha \pi \tau i \sigma \alpha \nu \tau o$ is commonly interpreted as a passive (see also the modern translations on the website http://biblehub.com/), but this reading is not convincing and the syntactic structure of the clause leads to another interpretation. The verb is combined with two locative complements which designate the cloud and the sea. These complements also occur in the pre- 
ceding clause: of [ART.NOM] $\pi \alpha \tau \varepsilon \dot{p} \varepsilon \varsigma$ [fathers:NOM] $\dot{\eta} \mu \hat{\omega} \nu$ [1PL.GEN] $\pi \dot{\alpha} \nu \tau \varepsilon \varsigma$ [QUANT.NOM] $v \pi \dot{o}$ [under] $\tau \dot{\eta} \nu$ [ART.ACC] $\nu \varepsilon \varphi \varepsilon ́ \lambda \eta \nu$ [cloud:ACC] $\hat{\eta} \sigma \alpha \nu$ [be:

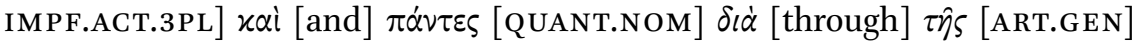
$\vartheta \alpha \lambda \alpha \dot{\sigma} \sigma \eta \varsigma$ [sea:GEN] $\delta i \hat{\imath} \lambda \theta 0 v$ [pass:AOR.ACT.3PL] (1 Corinthians 10:1) 'our fathers were all under the cloud, and all passed through the sea'. The reference to the Hebrews' flight from Egypt could also be a figure of speech for baptism. Modern commentaries on this passage point to the fact that "Paul reads the exodus story and the Christ event as a double exposure" (Montague 2011: 166). Because of this double reference, the verb $\dot{\beta} \beta \alpha \tau i \sigma \alpha \nu \tau$ could have two complementary readings. It can be interpreted as a true reflexive 'they dipped themselves' and refer to the real fact that the Hebrews dipped into the cloud and the sea, which are, respectively, the symbol of God in the Old Testament and the prefiguration of baptism. If the figured interpretation and the reference to baptism prevail, the verb can be read as a causative middle 'they got themselves baptised'. The passive reading 'they were baptised' is also possible, if we adopt the lectio facilior $\dot{\varepsilon} \beta \alpha \pi \tau i \sigma \theta \eta \sigma \alpha \nu$, accepted in the NA28 edition, instead of the lectio difficilior $\varepsilon \beta \alpha \pi \tau i \sigma \alpha \nu \tau$, transmitted by papyrus $\mathrm{P}^{46}$ of the Chester Beatty collection and accepted in both TLG and the Perseus Project. ${ }^{5}$

Both reflexive and middle causative analyses of $\dot{\varepsilon} \beta \alpha \pi \tau i \sigma \alpha \nu \tau 0$ are consistent with the other occurrences of the verb. In the aorist stem, the verb is attested $15^{\times}$as a passive aorist with passive ('I was baptised') and reflexive ('I washed myself') meanings, e.g. $(23 \mathrm{~b})-(23 \mathrm{c})$ respectively, and $8 \times$ as an active aorist with an active and transitive meaning ('I baptised'), e.g. (23d):
b. $\dot{\varepsilon} \beta \alpha \pi \tau i \sigma \vartheta n$
sis $\tau \dot{v} v$

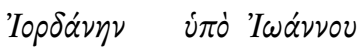
baptise:AOR.PASS.3SG in ART.ACC Jordan:ACC by John:GEN
'[Jesus] was baptised by John in the Jordan River' (Mark 1:9)

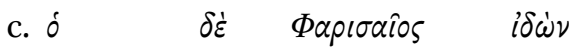

ART.NOM PTCL Pharisee:NOM seing:PTCP
$\varepsilon \vartheta \alpha u ́ \mu \alpha \sigma \varepsilon v$

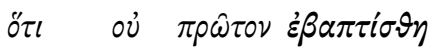
be.astonished:AOR.ACT.3SG COMP not first wash:AOR.PASS.3SG

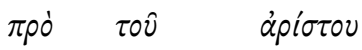

before ART.GEN dinner:GEN

'The Pharisee was astonished to see that he did not first wash [himself] before dinner' (Luke 11:38)

5 The issue of textual criticism of the NT is too complex to be discussed in detail. For an overview, I refer the reader to Aland \& Aland (1987: 83-102) and Metzger \& Ehrman (2005). 

d. ö $\tau$ l

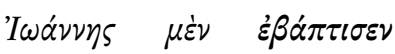
i $\delta \tau \iota$
COMP John:NOM PTCL baptise:AOR.ACT.3SG water:DAT
'For John baptised with water' (Acts 1:5)

The verb is also twice attested with middle morphology, here in $(23 \mathrm{e})-(23 \mathrm{f})$. In the first occurrence, the verb means 'to dip, to wash' and is a reflexive. The comparison with $(23 \mathrm{c})$, in which the reflexive is expressed by a passive aorist, clearly shows that the two voices are in competition. In the second occurrence $(=22 b)$, the verb means 'to baptise' and can be interpreted as a causative middle (lit. 'to get yourself baptised'), consistently with (23a):
e. $x \alpha i \quad \dot{\alpha} \pi^{\prime} \quad \dot{\alpha} \gamma o p a \hat{s}$
$\dot{\varepsilon} \dot{\alpha} \nu$
$\mu \dot{\eta} \beta \alpha \pi \tau i \sigma \omega \nu \tau \alpha l$
oủx
and from marketplace:GEN COMP not wash:AOR.MID.3PL not

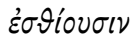
eat:PRS.ACT.3PL
'and when they come from the marketplace, they do not eat unless they wash' (Mark 7:4)

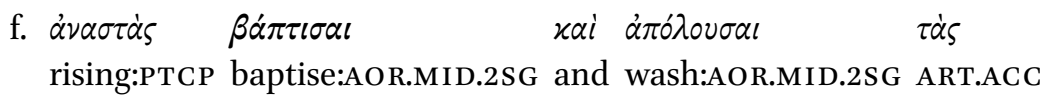

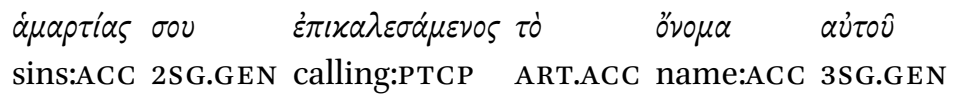 'Rise and get yourself baptised and wash away your sins, calling on his name' (Acts 22:16)

The problem concerning the interpretation of $\beta \alpha \pi \tau i \zeta \omega$ and its voices was posited by Moule (1959: 26) in his grammar of the NT. He lists the verb among "the specimens of problematic passages" and remarks: "[i]s there any significance in the comparison between Acts 9:18 $\alpha \nu \alpha \sigma \tau \dot{\alpha} \varsigma \dot{\varepsilon} \beta \alpha \pi \tau i \sigma \theta \eta$ and 22:16 $\dot{\alpha} \nu \alpha \sigma \tau \dot{\alpha} \varsigma$

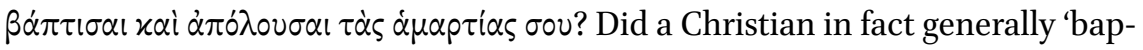
tize himself', 'get himself baptized', or 'submit to baptism'?". It is not surprising that the interpretation of the verb $\beta \alpha \pi \tau i \zeta \omega$, which designates one of the core notions and practices of Christianity, is so problematic. In this verb, indeed, the linguistic issue of diathesis, in its etymological meaning of 'disposition' (of the arguments), meets the issue of baptism, its sacral value and its theological meaning. Which semantic roles do the subject and the object display? Are they 'one who baptises' vs 'one who is baptised' or, rather, 'one who lets someone get baptised' vs 'one who gets baptised'? The answers to these questions are not trivial for Christian religion and theology. 
In grammars and studies concerning the diachronic changes in the verbal system of Ancient Greek, the most hotly debated topics are the changes in future expressions from analytic to periphrastic strategies, the restructuring of verbal aspects and the disappearance of the optative (cf., among others, Horrocks 2010: $82,102,130-131)$. As far as the aorist is concerned, the merging with the perfect yielded major changes in the tense and aspect systems; see chapters 1-4, 14 and 17 of the book recently edited by Runge \& Fresch (2016) and references therein. Not many studies have been devoted to the diachrony of the aorist voice system. Scholars limit themselves to remarking that passive aorists spread and middle aorists were reduced in number and were no longer productive (see the studies cited in Section 2 above). Since the aorist forms are the same as in Classical Greek, the functions are also expected to have been preserved, as Aubrey (2016: 620) argues for Hellenistic Greek: “- $(\theta) \eta$ - is used predominantly within its original five types, marking those events that shift the focus of attention to the more patient-like participant. The sigmatic middle aorist morphology predominantly marks the other middle types, which involve a more agent-like primary figure". This assumption proves to be mistaken, as I show in what follows; here, I compare the aorist voice system of the NT with that of Homeric and Classical Greek.

\subsection{Homeric Greek}

In Homeric poems two different systems of voice are attested for the aorist (cf. Benedetti 2017 for more details). In the first system, inflection (active vs middle) marks the opposition between active and middle/passive voice, as in the voice system of the present. This system is presumably inherited and is not productive. It is only found with root and thematic aorists, see (24) and (25) respectively, and occurs with a few verbal items. What is peculiar is that middle inflection also marks the passive, e.g. (24b) and $(25 b)$, compared with the active transitive in $(24 \mathrm{a})$ and $(25 \mathrm{a})$ :

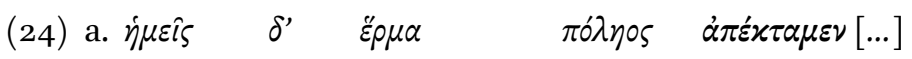

1PL.NOM PTCL bulwark:ACC city:GEN kill:AOR.ACT.1PL

'but we have killed the bulwark of the city' (Od. 23:121)

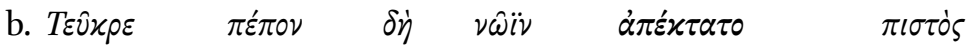

Teucer:VOC good:VOC PTCL 1DU.GEN kill:AOR.MID.3SG true:NOM

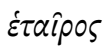

comrade:NOM

'Good Teucer, a true comrade of ours has been killed' (Il. 15:437) 


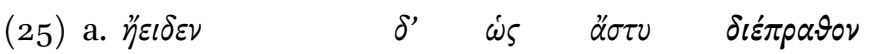

sing:AOR.ACT.3SG PTCL COMP city:ACC sack:AOR.ACT.3PL

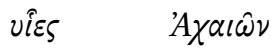

sons:NOM Achaeans:GEN

'he sang how the sons of the Achaeans sacked the city' (Od. 8:514)

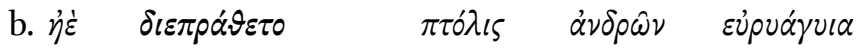

PTCL sack:AOR.MID.3SG city:NOM men:GEN with.wide.streets:NOM 'was a city of men sacked, which has wide streets?' (Od.15:384)

The second system involves the most productive aorist classes, namely the sigmatic and the passive aorists. Two patterns of voice markers characterise this system. On the one hand, the affixes $-\sigma \alpha-$ vs $-\eta-/-\theta \eta$ - codify the opposition between active and middle-intransitive, namely passive and unaccusative. On the other hand, the inflection (active vs middle) codifies the opposition between active and middle-transitive, namely reflexive, benefactive, reciprocal, etc. The three terms are exemplified in $(26 \mathrm{a})-(26 \mathrm{c})$ :

(26) a. 0

$\delta^{\prime} \quad i \pi \pi 0 v \varsigma \quad \mu \dot{\varepsilon} \nu \quad \lambda \hat{v} \sigma \alpha \nu \quad \dot{v} \pi \dot{0}$

ART.NOM PTCL horses:ACC PTCL loosen:AOR.ACT.3PL from

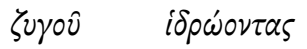

yoke:GEN sweating:PTCP

'their sweating horses they loosed from beneath the yoke' (Il. 8:543)

b. $\varepsilon \delta \delta \varepsilon \varepsilon \quad \delta^{\prime} \quad \dot{\alpha} \nu \alpha \varkappa \lambda \iota \nu \vartheta \varepsilon i \sigma \alpha, \quad \lambda \nu^{\prime} \vartheta \varepsilon \nu$

sleep:AOR.ACT.3SG PTCL sinking.back:PTCP loosen:AOR.PASS.3PL

$\delta \dot{\varepsilon} \quad$ oi $\quad \ddot{\psi} \psi \varepsilon \alpha \quad \pi \alpha \dot{\nu} \nu \tau$

PTCL 3SG.DAT joints:NOM QUANT.NOM

'and she sank back and slept, and all her joints relaxed' (Od. 4:794)

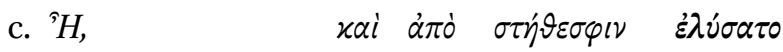

speak:PRS.ACT.3SG and from bosom:DAT loosen:AOR.MID.3SG

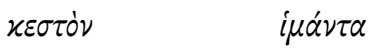

embroidered:ACC strap:ACC

'she spoke, and loosed from her bosom the embroidered strap'

(Il. 14:214)

In the pair (26a)-(26b), the opposition between active transitive and middleintransitive is marked by affixes, the inflection being active in both cases. In the pair (26a)-(26c), instead, the opposition between active transitive and middle- 
transitive is marked by inflection. The tripartite voice system is innovative with respect to the bipartite one, since it makes one further distinction within middle diathesis relevant, namely the syntactic difference between intransitive and transitive. The intransitive term is constituted by passives and unaccusatives. They are mostly expressed by passive aorists, but some sigmatic middles are also found in unaccusatives, e.g. (27a), besides passive aorists (27b). No sigmatic middles are found in the passive, however.
(27) a. $\ddot{\omega} \varsigma \quad \varphi \alpha^{\prime}$

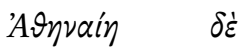
PTCL speak:IMPF.MID.3SG Athena:NOM PTCL

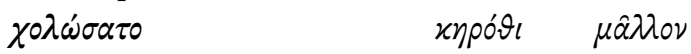
become.angry:AOR.MID.3SG heart:LOC more
'so he spoke, and Athena became the more angry at heart'
(Od. 22:224)

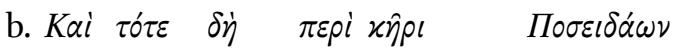
and PTCL PTCL at heart:DAT Poseidon:NOM

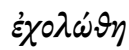
become.angry:AOR.PASS.3SG
'and then it was that Poseidon grew furious at heart' (Il.13:206)

The coexistence of the two forms in the same structure is evidence that the change is in progress. The verbal markers for the unaccusative are middle inflection in (27a) and the affix $-\theta \eta$ - in (27b). They relate to the bipartite and the tripartite voice systems, respectively. As we argue in Section 4.2, in Classical Greek there was a tendency to reduce redundancy, by selecting one of the two forms according to their transitive or intransitive behaviour.

Lastly, a remark about deponent verbs. In Homeric Greek they are mostly

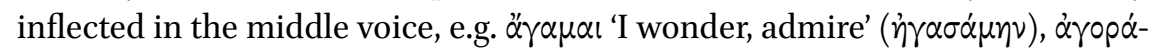

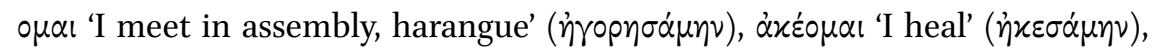

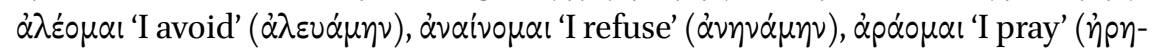

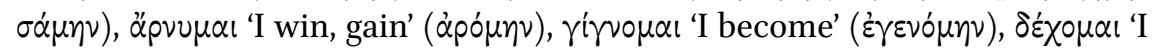

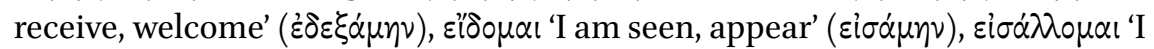

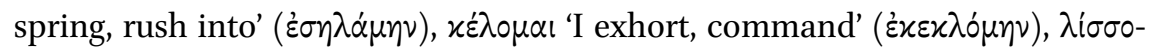

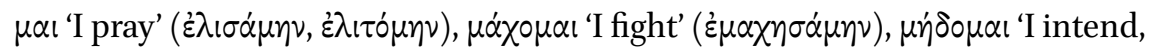

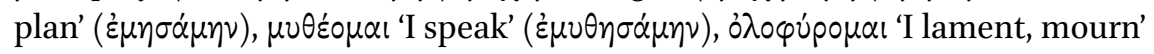

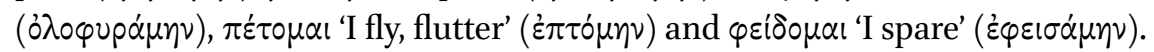

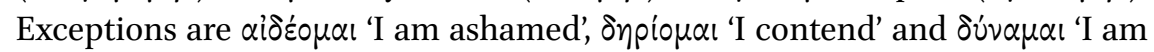

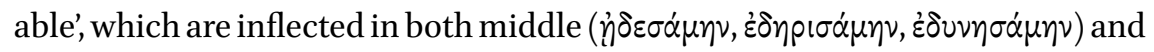

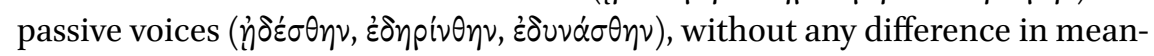


ing. Only the deponent $\alpha \lambda \alpha \dot{\alpha} \mu \alpha$ I 'I wander, roam' is exclusively inflected in the passive voice in Homeric Greek ( $\alpha \lambda \dot{\eta} \theta \eta \nu)$.

\subsection{Classical Greek}

The tripartite voice system increased in Classical Greek, since passive aorists spread and replaced middle aorists in unaccusatives. For instance, the verb xol$\mu \alpha \dot{\alpha}$ 'I put to sleep' is attested as both sigmatic middle (28a) and passive aorist (28b) in Homeric poems, but only occurs as passive aorist in Classical Greek

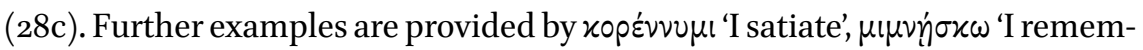
ber', o $\rho \mu \alpha \dot{\alpha} \omega$ 'I set in motion, start', $\pi \varepsilon ı \rho \alpha \omega$ 'I attempt, try' and the deponent verbs

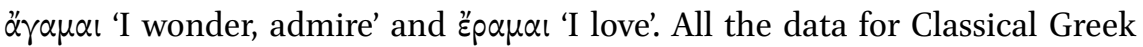
come from Xenophon's works.

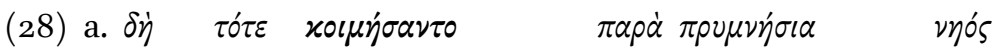
PTCL PTCL sleep:AOR.MID.3PL by stern.cables:ACC ship:GEN 'they slept by the stern cables of the ship' (Il.1:476)

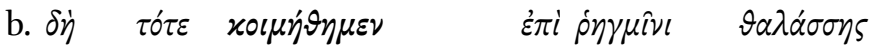

PTCL PTCL sleep:AOR.PASS.1PL on shore:DAT sea:GEN 'then we slept on the shore of the sea' (Od.4:575)

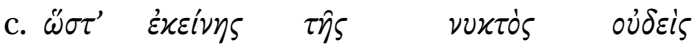
COMP DEM.GEN ART.GEN night:GEN nobody:NOM

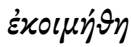
sleep:AOR.PASS.3SG 'and during that night no one slept' (X. HG. 2:2:3)

Sigmatic middles decreased in number and continued to exist in middle transitive structures, such as benefactives (29a) and possessives (30a); the corresponding active transitives are in (b).

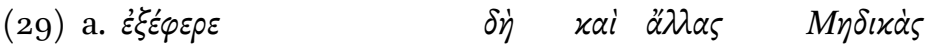
bring.out:IMPF.ACT.3SG PTCL and other:ACC Median:ACC

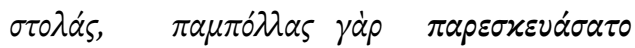
robes:ACC many:ACC PTCL provide:AOR.MID.3SG 'he brought out other Median robes, for he had provided a great many made' (X. Cyr. 8:3:3)

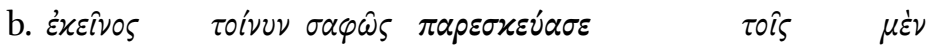
DEM.NOM PTCL clearly provide:AOR.ACT.3SG ART.DAT PTCL 


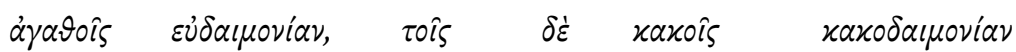
brave:DAT happiness:ACC ART.DAT PTCL coward:DAT misery:ACC 'Clearly, what he did was to provide happiness to the brave, and misery to the coward' (X. Lac. 9:3)

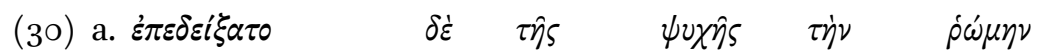

show:AOR.MID.3SG PTCL ART.GEN soul:GEN ART.ACC force:ACC 'And he displayed the stalwart nature of his heart' (X. Ap. 33)

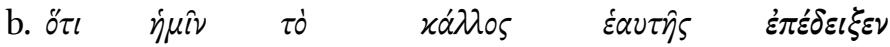

COMP 1PL.DAT ART.ACC beauty:ACC REFL.GEN show:AOR.ACT.3SG 'because she showed us her beauty' (X. Mem. 3:11:2)

Sigmatic middles also occur with deponent verbs, e.g. $\alpha \sigma \pi \alpha \dot{\alpha} \zeta \alpha \alpha$ ' 'I greet' ( $\dot{\eta} \sigma \pi \alpha-$

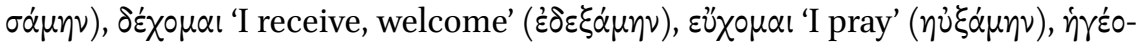

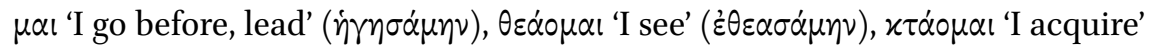

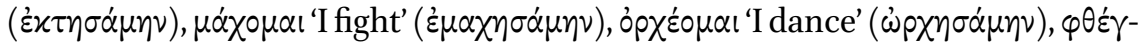

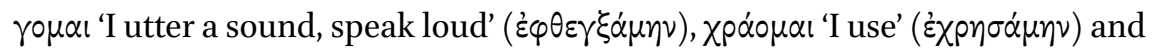

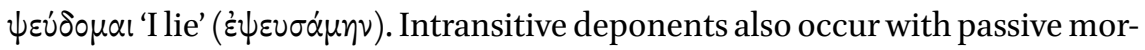

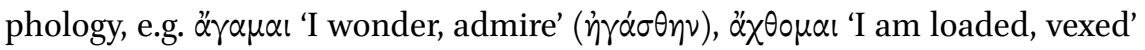

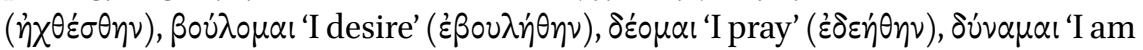

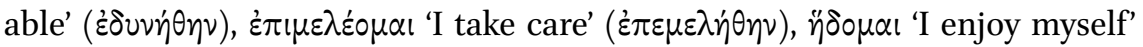

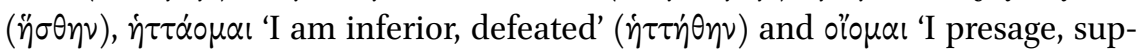
pose' ( $\left.\omega^{\prime} \theta \eta \nu\right)$. Among the quasi-deponents, it is worth mentioning the verb

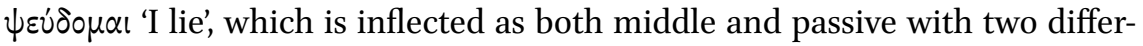
ent meanings: it is transitive in the middle and unaccusative in the passive.

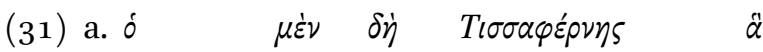

ART.NOM PTCL PTCL Tissaphernes:NOM REL.ACC

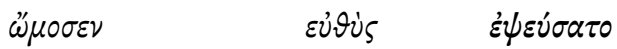

swear:AOR.ACT.3SG straightway violate:AOR.MID.3SG

'Now Tissaphernes straightway violated the oaths which he had sworn' (X. $H G .3: 4: 6$ )

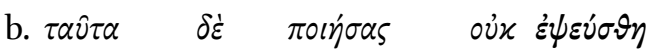

DEM.ACC PTCL doing:PTCP not be.disappointed:AOR.PASS.3SG

'Having done all these things he was not disappointed' (X. HG. 4:8:36)

Some evidence of the functional decrease of middle morphology is also given by pairs such as the following, in which the three-argument verb $\varkappa \alpha \tau \alpha \sigma \varkappa \varepsilon \cup \alpha \zeta \zeta \omega$ 
'I equip' occurs; see the active form in (32a). The verb with middle morphology in (32b) should be interpreted as a benefactive middle, but the occurrence of the dative reflexive pronoun shows that middle inflection is not sufficient to express the benefactive (in Italian, it would be literally translated 'si preparò per sé, with two redundant benefactive markers, the clitic "si" and the reflexive "per sé"):

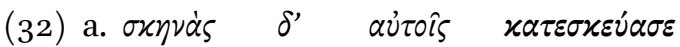
tents:ACC PTCL 3PL.DAT make:AOR.ACT.3SG 'Then, he made tents for them' (X. Cyr. 2:1:25)

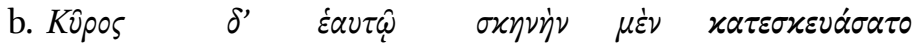
Cyrus:NOM PTCL REFL.DAT tent:ACC PTCL make:AOR.MID.3SG 'And for himself Cyrus made a tent' (X. Cyr. 2:1:30)

The bipartite system disappeared together with most of the forms which featured it in Homeric poems. In the thematic aorists which continued to exist in Classical Greek, middle forms never occurred in passive clauses, in which they were replaced by passive aorists, e.g. (33a); they sometimes occurred in unaccusatives, e.g. (33b), in which passive aorists could also occur however, e.g. (33c), and mostly occurred in middle transitives, e.g. (33d). See the verbs $\lambda \alpha \mu-$ $\beta \alpha \dot{\alpha} \omega \omega$ 'I take', which occurs as a passive within a passive clause in (33a) and as a middle within a middle transitive in (33b), $\dot{\alpha} \pi \dot{\alpha} \lambda \nu \mu \iota$ 'I kill', which occurs as a middle within an unaccusative in (33c) and $\alpha \dot{\alpha} \gamma \gamma \omega$ 'I lead up', which occurs as both middle and passive in unaccusatives in (33d)-(33e); on this use of $\alpha \dot{\alpha} \alpha \hat{\gamma}$ cf. $L S J$ s.v.

(33) a. oi

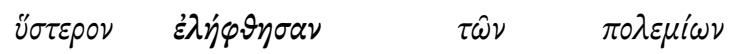

REL.NOM thereafter take:AOR.PASS.3PL ART.GEN enemies:GEN '[identical reports were made by those] who were taken prisoners thereafter' (X. An. 1:7:13)

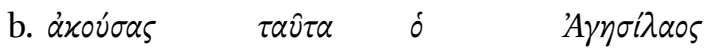
hearing:PTCP DEM.ACC ART.NOM Agesilaus:NOM

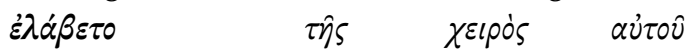
grasp:AOR.MID.3SG ART.GEN hand:GEN 3SG.GEN 'Upon hearing these words Agesilaus grasped his hand and said' (X. HG. 4:1:38) 


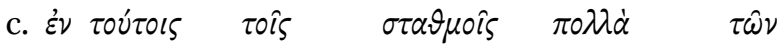

in DEM.DAT ART.DAT stages:DAT many:NOM ART.GEN

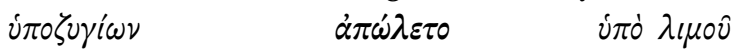

baggage.animals:GEN die:AOR.MID.3SG of hunger:GEN

'In the course of these stages many of the baggage animals died of hunger' (X. An. 1:5:5)

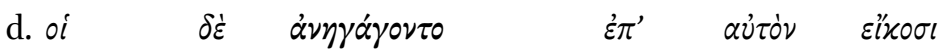

ART.NOM PTCL set.sail:AOR.MID.3PL against 3SG.ACC twenty vavoív

ships:DAT

'they put out against him with twenty ships' (X. HG. 1:1:2)

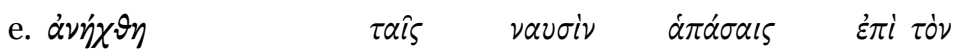
set.sail:AOR.PAss.3sG ART.DAT ships:DAT QUANT.DAT to ART.ACC

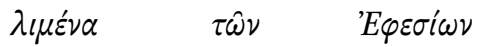

harbour:ACC ART.GEN Ephesians:GEN '[Alcibiades] set sail with all his ships to the harbour of Ephesus' (X. HG. 1:5:15)

Further thematic aorists attested as middles in Xenophon are عìó $\mu \eta \nu$ 'I caught'

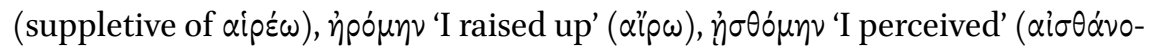

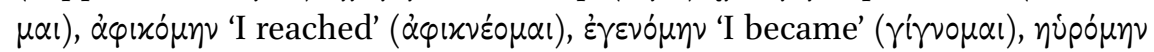

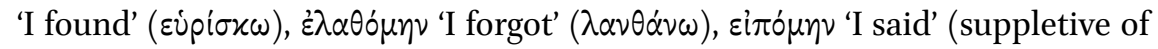

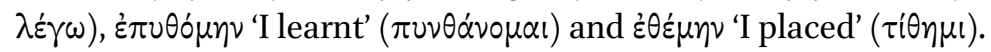

\section{5}

\section{Concluding remarks}

In this paper it has been pointed out that the aorist voice system changed in Hellenistic Greek with respect to Homeric and Classical Greek. The major changes concerned the middle and passive voices. Starting from Homeric Greek and even more in Classical Greek, sigmatic aorists and passive aorists became the most productive aorist classes. Sigmatic aorists display a bipartite voice system, based on inflection opposition. Passive aorists are opposed to sigmatic aorists through the affixes $-\theta \eta-/-\eta-v s-\sigma \alpha-$. The coexistence of these two classes created a tripartite voice system, which included (sigmatic) activeinflected forms, (sigmatic) middle-inflected forms and (passive) affixed forms. This system spread at the expense of the bipartite system, which only displayed inflection opposition, concerned thematic and root aorists and was attested in 
TABLE 3 Aorist voice system in NT Greek

\begin{tabular}{|c|c|c|c|}
\cline { 2 - 4 } \multicolumn{1}{c|}{} & \multicolumn{2}{c|}{ VOICE } \\
\cline { 2 - 4 } \multicolumn{1}{c|}{ Active } & \multicolumn{2}{c|}{ Middle } & Passive \\
\cline { 2 - 4 } & Transitive & Intransitive \\
\hline FORIST & $\begin{array}{c}\text { Active- } \\
\text { inflected } \\
\text { aorists }\end{array}$ & $\begin{array}{c}\text { Middle- } \\
\text { inflected } \\
\text { aorists }\end{array}$ & "Passive" aorists \\
\hline
\end{tabular}

Homeric Greek. In the tripartite system, the functional distribution of voice markers is as follows: active aorists occur in active clauses, passive aorists in passive and unaccusative clauses, and middle aorists in middle-transitive clauses, e.g. benefactives and possessives, in deponent verbs, and in some unaccusatives, e.g. Ė $\chi 0 \lambda \omega \sigma \alpha \dot{\mu} \mu \eta \nu$ 'I was angered' from $\chi 0 \lambda o^{\prime} \omega$ 'I anger'. In Classical Greek, a tendency towards a clearer distribution of voice markers developed, mostly in the middle. Passive aorists spread into unaccusatives and intransitive deponent verbs. Middle aorists increasingly occurred in middle-transitive structures. However, in some instances, e.g. (32b), middle inflection appears to be unable to express the middle meaning of the clause and other middle markers, e.g. reflexive pronouns, had to be used.

In the NT, the aorist voice system displays the same forms as Classical Greek, with some differences concerning their functional distribution. Passive aorists increasingly replaced middle aorists of deponent and quasi-deponent verbs,

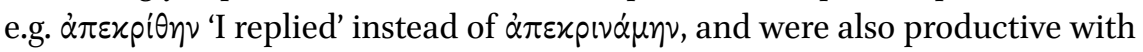
the new items, e.g. $\beta \alpha \pi \tau i \zeta \omega$ 'I baptise'. In brief, passive aorists spread in all intransitive uses of the middle. As far as middle aorists are concerned, they continued to exist and maintained middle transitive meanings, e.g. benefactives, possessives and so on. Most deponent transitives continued to be middleinflected in the aorist; in these verbs the opposition between middle and passive morphology was used to express the functional opposition between active and passive, e.g. (2Oa) - (20b). All these phenomena clearly show that the transitive vs intransitive feature became even more relevant in the middle voice and led to a reorganization of the functional distribution of aorist voice markers, as Table 3 roughly represents.

The expansion of passive aorists at the expense of middle aorists is not only a matter of forms that replace other forms; it also concerns the level 
of functions. In other words, the productivity of passive aorists in Hellenistic Greek is the effect, at the level of form, of the syntactic feature associated with them, namely intransitivity. As an oppositive term, transitivity is expressed by both active and middle aorists, middle inflection being completely defunctionalised as a voice marker, with some rare exceptions; see examples (5) and (6a) above.

So, in agreement with Blass, Debrunner \& Funk (1961: 180), we contend that "[ $t$ ] he system of three voices of the verb-active (transitive), passive (intransitive), and middle (i.e. transitive with reference to the subject) - remains on the whole the same in the NT as in the classical language". Our research allows us to add that the functional distribution of sigmatic middle and passive aorists changed in NT Greek, even though the forms seem to be the same as in Homeric and Classical Greek. In our opinion, the reorganisation of the middle markers on the basis of the transitive vs intransitive feature is the first step in the creation of the Modern Greek bipartite system. However, further studies are needed to investigate whether and how this feature spread in later Greek texts.

\section{Acknowledgments}

This research was carried out within the project Multilingualism and Minority Languages in Ancient Europe [HERA.29.015| CASsio], funded by Hera Joint Research Programme "Uses of the Past", Horizon 2020-649307. Many thanks to Marina Benedetti, Brian D. Joseph, and two anonymous reviewers for their insightful comments and suggestions, and to Elizabeth Rowley-Jolivet for her help with the English version of this paper.

\section{References}

Alexiadou, Artemis \& Edith Doron. 2012. The syntactic construction of two non-active voices: passive and middle. Journal of Linguistics 48(1): 1-34.

Aland, Kurt \& Barbara Aland. 1987. The text of the New Testament. An introduction to the critical editions and to the theory and practice of modern textual criticism. Leiden: Brill / Grand Rapids: Eerdmans (English translation of Der Text des Neuen Testaments by Erroll F. Rhodes).

Allan, Rutger J. 2003. The middle voice in Ancient Greek. A study in polysemy. Amsterdam: Gieben.

Allan, Rutger J. 2014a. Diathesis/Voice (Morphology of). Encyclopedia of Ancient Greek 
language and linguistics, ed. by Georgios K. Giannakis, vol. I, 471-475. Leiden/ Boston: Brill.

Allan, Rutger J. 2014b. Voice. Encyclopedia of Ancient Greek language and linguistics, ed. by Georgios K. Giannakis, vol. III, 494-502. Leiden/Boston: Brill.

Ambrosini, Riccardo. 1996. La diatesi passiva nelle lingue indoeuropee. Pisa: ETs.

Aubrey, Rachel. 2016. Motivated categories, middle voice, and passive morphology. The Greek verb revisited. A fresh approach for biblical exegesis, ed. by Steven E. Runge \& Christopher J. Fresch, 563-625. Bellingham, wA: Lexham Press.

Bakker, Egbert J. 1994. Voice, aspect and aktionsart: Middle and passive in Ancient Greek. In Voice: Form and function, ed. by Barbara Fox and Paul Hopper, 23-47. Amsterdam: Benjamins.

Benedetti, Marina. 2005. Dispersioni formali del medio indoeuropeo. Acquisizione e mutamento di categorie linguistiche. Atti del Convegno della Società Italiana di Glottologia (Perugia, 23-25 ottobre 2003), ed. by Lidia Costamagna and Stefania Giannini, 95-119. Roma: Il Calamo.

Benedetti, Marina. 2006. Mehr als passiv: über einige Verbalmorpheme in altindogermanischen Sprachen. International journal of diachronic linguistics and linguistic reconstruction 3: 91-110.

Benedetti, Marina. 2017. Quale medio, quale passivo? Riflessioni sulla diatesi in greco. Studi e Saggi Linguistici 55(1): 47-63.

Blass, Friedrich, Albert Debrunner \& Robert W. Funk. 1961 [1896]. A Greek grammar of the New Testament and other early Christian literature. 1oth edition. Chicago: University of Chicago Press.

Browning, Robert. 1983 [1969]. Medieval and Modern Greek. 2nd edition. London: Hutchinson University Library.

Buth, Randall. 1984. Hebrew poetic tenses and the Magnificat. Journal for the study of the New Testament 6(21): 67-83.

Campbell, Constantine R. 2015. Advances in the study of Greek. New insights for reading the New Testament. Michigan, Grand Rapids: Zondervan.

Caragounis, Chrys C. 2004. The development of Greek and the New Testament: Morphology, syntax, phonology, and textual transmission. Tübingen: Mohr Siebeck.

Carroll, John T. 2012. Luke: A commentary. Louisville, KY: Westminster John Knox Press.

Grestenberger, Laura. 2014. Feature mismatch: Deponency in Indo-European languages. Harvard University: PhD Thesis.

Hatzidakis, Georgios N. 1892. Einleitung in die neugriechische Grammatik. Leipzig: Breitkopf.

Hays, Richard B. 2011. First Corinthians. Louisville, KY: Westminster John Knox Press.

Horrocks, Geoffrey. 2010 [1997]. Greek. A history of the language and its speakers. 2nd edition. Chichester: Wiley-Blackwell.

Jankuhn, Harald. 1969. Die passive Bedeutung medialer Formen. Untersucht an der Sprache Homers. Göttingen: Vandenhoeck and Ruprecht. 
Jannaris, Antonius N. 1897. An Historical Greek grammar, chiefly of the Attic Dialect as written and spoken from Classical Antiquity down to the present time, founded upon the ancient texts, inscriptions, papyri and present popular Greek. London: Macmillan.

Kemmer, Suzanne. 1993. The middle voice. Amsterdam: Benjamins.

Kittel, Gerhard \& Gerhard Friedrich. 1932-1936. Theologisches Wörterbuch zum Neuen Testament. Stuttgart: Kohlhammer.

Kühner, Raphael \& Bernhard Gerth. 1892. Ausführliche Grammatik der griechischen Sprache. Erster Teil: Elementar- und Formenlehre. Zweiter Band. Hannover: Hahn.

Kühner, Raphael \& Bernhard Gerth. 1898. Ausführliche Grammatik der griechischen Sprache. Zweiter Teil: Satzlehre. Erster Band. Hannover: Hahn.

Kulikov, Leonid. 2010. Voice typology. The Oxford handbook of linguistic typology, ed. by Jae Jung Song, 368-398. Oxford: Oxford University Press.

Kulikov, Leonid. 2013. Middle and reflexive. The Bloomsbury companion to syntax, ed. by Silvia Luraghi \& Claudia Parodi, 261-28o. London/New Delhi/New York/Sydney: Bloomsbury.

Kulikov, Leonid \& Nikolaos Lavidas. 2013. Reconstructing passive and voice in ProtoIndo-European. Journal of historical linguistics 3(1): 98-121.

Ladewig, Stratton L. 2010. Defining deponency: An investigation into Greek deponency of the middle and passive voices in the Koine period. Dallas Theological Seminary: $\mathrm{PhD}$ Thesis.

La Fauci, Nunzio \& Liana Tronci. 20o9. Verb inflection in Ancient Greek and Sanskrit and auxiliation patterns in French and Italian. Functions, forms, system. Lingvisticae Investigationes 32(1): 55-76.

Lavidas, Nikolaos. 2009. Transitivity alternations in diachrony: Changes in argument structure and voice morphology. Newcastle-upon-Tyne: Cambridge Scholars Publishing.

Lavidas, Nikolaos \& Dimitra Papangeli. 2007. Deponency in the diachrony of Greek. Deponency and morphological mismatches, ed. by Matthew Baerman, Greville G. Corbett, Dunstan Brown and Andrew Hippisley, 97-126. Oxford: Oxford University Press.

LSJ: Liddell, Henry G., Robert Scott \& Henry S. Jones. 1996 [1843]. Greek-English lexicon. 9th edition. Oxford: Clarendon Press.

Mayser, Edwin. 1906. Grammatik der griechischen Papyri aus der Ptolemäerzeit mit Einschluss der gleichzeitigen Ostraka und der in Ägypten verfassten Inschriften. Laut- und Wortlehre. Leipzig: Teubner.

McKay, Kenneth L. 1994. A new syntax of the verb in New Testament Greek. An aspectual approach. New York: Peter Lang.

Méndez, Hugo. 2016. Semitic poetic techniques in the Magnificat: Luke 1:46-47, 55 . Journal of Biblical literature 135(3): 557-574. 
Metzger, Bruce M. \& Bart D. Ehrman. 2005 [1964]. The text of the New Testament. Its transmission, corruption, and restoration. 4 th edition. Oxford: Oxford University Press.

Montague, George T. 2011. First Corinthians. Grand Rapids, MI: Baker Academic.

Moule, Charles F.D. 1959. An idiom book of New Testament Greek. Cambridge: Cambridge University Press.

Moulton, James H. 1906 [1905]. A grammar of New Testament Greek. Vol. I:Prolegomena. 2nd edition. Edinburgh: T. \& T. Clark.

Phillips, John. 2002. Exploring ${ }_{1}$ Corinthians: An expository commentary. Grand Rapids, MI: Kregel.

Plummer, Alfred. 1960 [1896]. A critical and exegetical commentary on the Gospel according to s. Luke. $5^{\text {th }}$ edition. Edinburgh: T. \& T. Clark.

Porter, Stanley E. 200oa. Dialect and register in the Greek of the New Testament:Theory. Rethinking contexts, rereading texts. Contributions from the social sciences to biblical interpretation, ed. by M. Daniel Carroll R., 190-208. Sheffield: Sheffield Academic Press.

Porter, Stanley E. 20oob. Register in the Greek of the New Testament: Application with reference to Mark's Gospel. Rethinking contexts, rereading texts. Contributions from the social sciences to biblical interpretation, ed. by M. Daniel Carroll R., 209-229. Sheffield: Sheffield Academic Press.

Prévot, André. 1935. L'aoriste grec en - $\theta \eta v$. Paris: Champion.

Rijksbaron, Albert. 2002 [1984]. Syntax and semantics of the verb in Classical Greek: An introduction. 3rd edition. Amsterdam: Gieben.

Risselada, Rodie. 1987. Voice in Ancient Greek: Reflexives and passives. Ins and outs of the predication, ed. by Johann van der Auwera \& Louis Goossens, 123-136. Dordrecht: Foris.

Robertson, Archibald T. 1934. A Grammar of the Greek New Testament in the light of historical research. New York: Hodder \& Stoughton.

Runge, Steven E. \& Christopher J. Fresch (eds.). 2016. The Greek verb revisited. A fresh approach for biblical exegesis. Bellingham, wA: Lexham Press.

Schwyzer, Eduard. 1990 [1953]. Griechische Grammatik. Erster Band. München: C.H. Beck.

Thayer, Joseph H. 1995 [1889]. Thayer's Greek-English Lexicon of the New Testament: Coded with Strong's concordance numbers. Peabody, MA: Hendrickson Publishers.

Tronci, Liana. 2005. Gli aoristi con - $(\vartheta) \eta$-: uno studio sulla morfosintassi verbale del greco antico. Perugia: Guerra.

Tronci, Liana. 2011. Taxonomie der Mediumkonstruktionen und Verbalflexion im Altgriechischen. Indogermanistik und Linguistik im Dialog. Akten der XIII. Fachtagung der Indogermanischen Gesellschaft vom 21. Bis 27. September 2008 in Salzburg, ed. by Thomas Krisch \& Thomas Lindner, 585-594. Wiesbaden: Reichert. 
Tronci, Liana. 2014. Formes moyennes oppositives et non oppositives. Brèves notes sur le grec ancien. Langages 194(2): $35^{-47}$.

Tronci, Liana. 2017. Le futur grec et son rapport au moyen. The Greek future and its history. Les futurs grecs et leur histoire, ed. by Frédéric Lambert, Rutger J. Allan \& Theodoros Markopoulos, 193-21o. Louvain-la-Neuve: Peeters.

Tronci, Liana. Forthcoming. Middle voice in Hellenistic Greek. A pilot study in the Gospel of Matthew. Proceedings of the 13th International Conference of Greek Linguistics (ICGL13).

Wackernagel, Jacob. 1926. Vorlesungen über Syntax. Vol. 1. Basel: E. Birkhäuser \& Cie. 